\title{
Inhibition of Transmitter Release Correlates with the Proteolytic Activity of Tetanus Toxin and Botulinus Toxin A in Individual Cultured Synapses of Hirudo medicinalis
}

\author{
Dieter Bruns, ${ }^{1}$ Silke Engers, ${ }^{1}$ Clement Yang, ${ }^{1}$ Rainer Ossig, ${ }^{2}$ Andreas Jeromin, ${ }^{2}$ and Reinhard Jahn ${ }^{1,2}$ \\ ${ }^{1}$ The Howard Hughes Medical Institute and ${ }^{2}$ Department of Pharmacology, Yale University School of Medicine, New \\ Haven, Connecticut 06510
}

\begin{abstract}
We have studied the effects of tetanus toxin and botulinus toxin $A$ on neurotransmitter release in the Retzius $\rightarrow P$-cell synapse of the leech and exploited the unique properties of this system, which allow for combined physiological and biochemical analyses in single-cell pairs. The sequences of Hirudo medicinalis synaptobrevin and synaptosomal-associated protein of $25 \mathrm{kDa}$ (SNAP-25), deduced by cDNA cloning, are 61 and $55 \%$ identical, respectively, to their corresponding mammalian homologs. Whereas Hirudo synaptobrevin is proteolyzed by tetanus toxin, its SNAP-25 isoform is resistant to botulinus toxin A cleavage because of amino acid substitutions within and around the putative cleavage site. In close correlation, microinjection of tetanus toxin into the presynaptic neuron produced a block of transmitter release, whereas botulinus toxin A had no effect on synaptic transmission. Subsequent immunoblotting of single-cell pairs demonstrated directly that the tetanus toxinmediated block of exocytosis is accompanied by cleavage of
\end{abstract}

synaptobrevin in the injected neuron, resulting in the generation of a detectable C-terminal cleavage product. Immunoblotting also confirmed the resistance of SNAP-25 to botulinus toxin A cleavage in vivo. Using recombinant proteins, we show that the $\mathrm{N}$-terminal fragment of synaptobrevin released by tetanus toxin, but not its C-terminal membrane-anchored cleavage product, participates with syntaxin and SNAP-25 in synaptic SNAP receptor (SNARE) ternary complex formation in Hirudo. Our data demonstrate a direct correlation between the inhibition of transmitter release and the ability of the neurotoxin to proteolyze its target protein and support the view that SNARE ternary complex formation is an important step leading to synaptic vesicle exocytosis.

Key words: transmitter release; synaptobrevin; VAMP; SNAP25; SNARE; tetanus toxin; botulinus toxin A; single-cell immunoblotting; Hirudo medicinalis
Calcium-regulated exocytosis of synaptic vesicles is the primary means of communication between neurons. A complex of conserved cytosolic proteins known as NSF ( $N$-ethylmaleimidesensitive fusion protein) and SNAP proteins (soluble NSF attachment proteins) is required for various intracellular fusion events in eukaryotic cells (Ferro-Novick and Jahn, 1994; Südhof, 1995; Calakos and Scheller, 1996; Rothman and Wieland, 1996). The search for neuronal membrane receptors (SNAREs, SNAP receptors) for these soluble "fusion" factors led to the identification of the vesicle protein synaptobrevin (VAMP) and the plasma membrane proteins, syntaxin and SNAP-25 (synaptosomal-associated protein of $25 \mathrm{kDa}$ ) (Söllner et al., 1993a).

Synaptobrevins are class II integral membrane proteins that expose most of their sequence at the cytoplasmic face of secretory vesicles (Südhof, 1995). SNAP-25 is an abundant highly conserved membrane-associated protein (Oyler et al., 1989; Risinger et al., 1993). It is post-translationally modified by palmitoyl side chains that mediate membrane binding (Hess et al., 1992; Veit et al., 1996).

Received Oct. 28, 1996; revised Dec. 19, 1996; accepted Dec. 30, 1996.

This work was supported by a Deutsche Forschungsgesellschaft fellowship to R.O. We thank Roberta Allen (The Salk Institute, La Jolla, CA) for the gift of the Hirudo nerve cord cDNA library, Thomas C. Südhof (University of Texas, Southwestern, Dallas, TX) for the cDNA of rat SNAP-25B, and Heiner Niemann (MH Hannover, Hannover, Germany) for tetanus toxin light chain, botulinus toxin A, and the cDNA of botulinus toxin A light chain. We thank P. Hanson and D. Fasshauer for suggestions on this manuscript.

Correspondence should be addressed to Dr. Dieter Bruns, The Howard Hughes Medical Institute, Yale University School of Medicine, 295 Congress Avenue, New Haven, CT 06510.

Copyright (C) 1997 Society for Neuroscience $0270-6474 / 97 / 171898-13 \$ 05.00 / 0$
Syntaxin is a similarly abundant small integral membrane protein with a C-terminal transmembrane domain (Bennett et al., 1992).

In detergent extracts of brain membranes, synaptobrevin, SNAP-25, and syntaxin are associated in a stable 7S complex (Söllner et al., 1993a,b). This synaptic SNAP receptor complex (SNARE) binds $\alpha$-SNAP and NSF to form a 20S particle. Because the SNARE complex involves proteins from both the vesicle membrane (synaptobrevin, v-SNARE) and the plasma membrane (SNAP-25 and syntaxin, t-SNARE), it has been proposed that the selectivity of pairing between v- and t-SNARE enables the docking of the vesicle at the intended target membrane (Söllner et al., 1993a; Pevsner et al., 1994). The immediate involvement of NSF and $\alpha$-SNAP in vesicle docking and fusion (Söllner et al., 1993b) recently has been questioned by the observation that yeast vacuoles can dock and fuse after Sec18p (NSF) has released Sec17p ( $\alpha$-SNAP) from the membrane, suggesting a predocking role of both proteins (Mayer et al., 1996).

Strong evidence that synaptobrevin, SNAP-25, and syntaxin are essential for $\mathrm{Ca}^{2+}$-regulated exocytosis was provided by the finding that these proteins serve as targets of the clostridial neurotoxins, which are potent inhibitors of neurotransmitter release. These neurotoxins are composed of two disulfide-linked polypeptide chains (Niemann, 1991; Montecucco and Schiavo, 1994; Niemann et al., 1994). The heavy chain (HC, $100 \mathrm{kDa}$ ) is involved in binding and internalization of the light chain (LC, $50 \mathrm{kDa})$, which in turn is responsible for the intracellular blockade of transmitter release. The light chain of clostridial neurotoxins was demonstrated to be a $\mathrm{Zn}^{2+}$ endopeptidase (Niemann et al., 1994). Tetanus neurotoxin 
light chain (TeNT-LC) cleaves synaptobrevin at the peptide bond between Gln76 and Phe77 (Schiavo et al., 1992). Botulinus neurotoxin A (BoNT/A) cleaves SNAP-25 at a site nine amino acids upstream from its $\mathrm{C}$ terminus between residues Gln197 and Arg198 (Blasi et al., 1993a; Schiavo et al., 1993; Binz et al., 1994).

Although in vitro studies have demonstrated specific proteolysis of the identified substrate proteins, little is known about the molecular mechanism of neurotoxin action in the functioning neuron. For instance, cleavage products of synaptobrevin generated by TeNT in vivo have not yet been characterized. Understanding of the proteolytic activity in the intact neuron is important for assessing the functional significance of the substrate protein itself and of protein complexes detected in vitro.

Here we investigate the effects of toxin poisoning at the singlecell level with electrophysiological and biochemical techniques, using the cultured Retzius $\rightarrow \mathrm{P}$-cell synapse of the leech (Hirudo medicinalis). The effects of two neurotoxins, TeNT and BoNT/A, were studied. When Retzius cells are paired with P-cells, a stable serotonergic synapse with well defined physiological properties is established (Fuchs et al., 1982; Dietzel et al., 1986; Bruns et al., 1993; Bruns and Jahn, 1995). Furthermore, the large-sized Retzius cell forms its synaptic contact with the postsynaptic P-cell over a short distance (Liu and Nicholls, 1989), making this preparation well suited for microinjection of neurotoxins.

We cloned the leech homologs of synaptobrevin and SNAP-25, generated antibodies to study the susceptibility of the proteins to neurotoxin cleavage, and established a method that allows us to detect the proteins in individual cultured neurons by immunoblotting. Our data show that leech synaptobrevin is sensitive to TeNT and demonstrate that inhibition of transmitter release correlates with cleavage of synaptobrevin in the presynaptic neuron. A C-terminal cleavage product of synaptobrevin was detected in vitro and in vivo that is not degraded further but fails to participate in SNARE ternary complex formation. This suggests that a block of exocytosis is caused by severing the membrane-anchored fragment of synaptobrevin from its complex-forming domain. In contrast, BoNT/A does not cleave leech SNAP-25 and has no effect on synaptic transmission, supporting the view that SNAP-25 is the sole target protein of BoNT/A.

\section{MATERIALS AND METHODS}

Animals. Experiments were performed on cells and nerve cord homogenate of adult leeches (Hirudo medicinalis) kept in laboratory aquaria.

Materials. Standard buffer contained (in $\mathrm{mM}$ ): $145 \mathrm{NaCl}$ and 25 HEPES-NaOH, pH 7.3. The monoclonal antibody $(\mathrm{Cl} 69.1)$ used for immunoblotting of rat synaptobrevin has been described previously (Edelmann et al., 1995).

Molecular cloning of cDNA encoding for synaptobrevin and SNAP-25 from $\mathrm{H}$. medicinalis. A $\lambda$-ZAP library that had been made to randomly primed Hirudo leech nerve cord mRNA (kindly provided by Roberta Allen and Steve Heinemann, The Salk Institute, La Jolla, CA) was screened at high stringency with a cDNA probe, which was generated by PCR (Saiki et al., 1988), using sets of degenerated oligonucleotide primers. Primers for SNAP-25 cloning were complementary to codons of amino acid positions 22-27 and 70-75 of mouse SNAP-25 (Oyler et al., 1989). Primers for synaptobrevin cloning corresponded to codons of amino acids 32-37 and 94-99 of rat synaptobrevin II (Elferink et al., 1989). The PCR isolates were subcloned into pCRII (Invitrogen, Portland, OR). Duplicate plaque lifts of $\sim 300,000$ plaques, plated at a density of 20,000 plaques per $150 \mathrm{~mm}$ Petri dish, were screened with the nucleotide insert of pCRII labeled by random oligonucleotide-primed synthesis with $\left[\alpha{ }^{32} \mathrm{P}\right] \mathrm{dCTP}(3000 \mathrm{Ci} / \mathrm{mmol}$, New England Nuclear, Boston, MA; Megaprime DNA labeling system, Amersham, Arlington Heights, IL). Hybridization conditions were $500 \mathrm{mM} \mathrm{Na}{ }_{2} \mathrm{HPO}_{4}, 7 \%$ SDS (w/w), $1 \%$ bovine serum albumin (w/w), $1 \mathrm{~mm}$ EDTA, and $50 \mu \mathrm{g} / \mathrm{ml}$ salmon sperm at $65^{\circ} \mathrm{C}$. The filters were washed with $2 \times \mathrm{SSC}, 1 \times \mathrm{SSC}$, and $0.2 \times \mathrm{SSC}$
( $1 \times \mathrm{SSC}$ is $150 \mathrm{~mm} \mathrm{NaCl}$ and $15 \mathrm{~mm}$ sodium citrate) with $0.2 \%$ SDS at $65^{\circ} \mathrm{C}$ and autoradiographed. Strongly positive clones for SNAP-25 and for synaptobrevin were plaque-purified. The excised pBluescript II $\mathrm{SK}^{-}$ (ExAssist Helper Phage System, Stratagene, La Jolla, CA) served for DNA sequencing on both strands, using the dideoxy chain termination method (Sanger et al., 1977). The syntaxin isoform from H. medicinalis was cloned by the same procedures and will be described in detail elsewhere. The nucleotide sequences reported in this paper have been submitted to the GenBank/European Molecular Biology Laboratory (EMBL) Data Bank with accession numbers U85805 for H. medicinalis synaptobrevin, U85806 for $H$. medicinalis SNAP-25, and U85807 for $H$. medicinalis syntaxin.

Generation of recombinant fusion proteins. Full-length and truncated coding sequences were amplified with PCR ( $P f u$ polymerase, Stratagene, La Jolla, CA), with oligonucleotides containing appropriate restriction sites for subsequent subcloning into the desired plasmids. Two vector systems were used to generate fusion proteins in Escherichia coli. Expressions in pTrcHis A (Invitrogen) generate fusion proteins in which six histidine residues and a 36-amino-acid linker sequence are fused to the $\mathrm{N}$ terminus of the coding sequence. The $\mathrm{His}_{6}$ fusion protein was purified on a Ni-Sepharose matrix (ProBond, Invitrogen) according to the manufacturer's instructions, and the protein was eluted with buffer containing 40, $80,120,240$, and $500 \mathrm{~mm}$ imidazole, $\mathrm{pH}$ 7.8. Expressions in pGEX-4T (Pharmacia, Piscataway, NJ) generated fusion proteins with glutathione $S$-transferase (GST). GST fusion proteins were purified essentially as described (Chapman et al., 1994) except that a TRIS-buffered saline (20 $\mathrm{mm}$ Tris, pH 7.5, $150 \mathrm{~mm} \mathrm{NaCl}, 1 \mathrm{~mm}$ EGTA, and $0.5 \mathrm{~mm}$ dithiothreitol) was used as the primary buffer. Column eluates were analyzed for purity by SDS-PAGE and staining with Coomassie blue. Full-length SNAP-25 was introduced into pTrcHis A as a Bam HI/EcoRI fragment. The cDNA encoding the amino acids 1-273 (comprising the entire cytoplasmic domain) of leech syntaxin was cloned into pGEX $4 \mathrm{~T}$ also as a Bam HI/ EcoRI fragment. Purified proteins were dialyzed against standard buffer, and aliquots were snap-frozen and stored at $-70^{\circ} \mathrm{C}$.

Production of antibodies: rabbit antisera recognizing leech proteins. Bam HI/Eco RI fragments encoding the amino acids 112-212 of SNAP-25 and 114-169 of synaptobrevin were subcloned into pTrcHis A. Aliquots of both fusion proteins ( $350 \mu \mathrm{g}$ in Freund's adjuvant) were used for the repeated immunization of New Zealand rabbits. Resulting polyclonal antisera (R37, synaptobrevin; R50, SNAP-25) were immunoaffinitypurified by using the antigen expressed as GST fusion protein coupled to CNBr-activated Sepharose 4B (Pharmacia). Purification was performed according to the manufacturer's instructions. The SNAP-25 antibody (R50) was affinity-purified with an antigen comprising the amino acid positions 112-204 of SNAP-25 to ensure that the full-length protein and a putative proteolytic fragment were recognized with equal affinities.

A new monoclonal antibody $(\mathrm{Cl} 71.1)$ recognizing rat SNAP-25B was generated. Recombinant SNAP-25 full-length was expressed as a $\mathrm{His}_{6}$ fusion protein and used for the immunization of Balb/c mice. Fusion, propagation, and screening were performed according to standard procedures (Köhler and Milstein, 1975; Jahn et al., 1985).

In vitro transcription-translation. cDNA encoding rat SNAP-25B has been described previously (Chapman et al., 1994) and was provided by T. C. Südhof (University of Texas, Southwester, Dallas, TX). Site-directed mutagenesis of leech synaptobrevin and SNAP-25 was performed by the overlapping primer method of Higuchi (1990). The same method was used to generate chimeras between leech and rat SNAP-25. Mutations were verified by DNA sequencing. cDNAs encoding wild-type and mutant leech SNAP-25 sequences were placed under control of the T7 promotor by subcloning into pBluescript $\mathrm{SK}^{-}$, which contained a polylinker deriving from pcDNAINEO (Invitrogen). cDNAs encoding for wild-type and mutant leech synaptobrevin were placed under control of an SP6 promoter by introducing into pSP64 (Promega, Madison, WI). Radiolabeled proteins were generated by coupled in vitro transcription-translation (reaction volume $25 \mu \mathrm{l}$ ) using the TNT system (Promega) in the presence of $\left[{ }^{35} \mathrm{~S}\right]$-methionine, according to the manufacturer's instructions. Fulllength synaptobrevin was translated in the presence of canine microsomal membranes (Boehringer Mannheim, Indianapolis, IN). At the end of the translation period, membranes were washed, recovered by centrifugation at 50,000 rpm for $20 \mathrm{~min}$ in a Beckman TLA 100.3 rotor, and resuspended in $25 \mu \mathrm{l}$ of standard buffer. This procedure reduced the content of globin (intrinsic to the TNT system) in the reaction mixture, preventing deterioration of the migratory properties of leech synaptobrevin and its cleavage products. The reaction product either was analyzed directly by SDS-PAGE and fluorography or was solubilized in standard buffer con- 
taining $0.5 \%$ Triton X-100, centrifuged (as described above) to remove insoluble material, and used for TeNT-LC incubations and the binding to glutathione-Sepharose-immobilized proteins.

Preparation of leech nerve cord and rat brain homogenate. Chains of segmental ganglia of six leeches were dissected out in ice-cold Ringer's (130 mM NaCl, $4 \mathrm{~mm} \mathrm{KCl}, 1 \mathrm{~mm} \mathrm{CaCl}$, and $10 \mathrm{~mm}$ HEPES-NaOH, $\mathrm{pH}$ 7.3). Nerve cords were washed in ice-cold standard buffer, supplemented with phenylmethylsulfonyl fluoride $(1 \mathrm{mM})$, leupeptin $(10 \mu \mathrm{g} / \mathrm{ml})$, pepstatin $\mathrm{A}(1 \mu \mathrm{M})$, and aprotinin $(2.5 \mu \mathrm{g} / \mathrm{ml})$, and homogenized in a volume of $250 \mu \mathrm{l}$ with a microscale tissue grinder $(0.1 \mathrm{ml})$. Protein concentration $(2.0 \mathrm{mg} / \mathrm{ml})$ was determined according to Bradford (1976). Preparation of rat brain homogenate (LP1 fraction) was performed as described (WalchSolimena et al., 1995).

Treatment with clostridial neurotoxins. TeNT-LC $(1 \mathrm{mg} / \mathrm{ml})$, BoNT/A holotoxin $(1 \mathrm{mg} / \mathrm{ml})$, and the cDNA for BoNT/A-LC were kindly provided by $\mathrm{H}$. Niemann (MH Hannover, Hannover, Germany). BoNT/ A-LC chain containing a C-terminal $\mathrm{His}_{6}$-tag was expressed in E. coli and purified by binding to a Ni-Sepharose matrix as described above. Fractions were analyzed for purity by SDS-PAGE and staining with Coomassie blue and dialyzed against standard buffer. BoNT/A-LC concentration $(2.0 \mathrm{mg} / \mathrm{ml})$ was determined according to Bradford (1976). Aliquots were snap-frozen and stored at $-70^{\circ} \mathrm{C}$. In vitro translated synaptobrevin and SNAP-25 (15 $\mu \mathrm{l}$ of the transcription-translation reaction mixture) were incubated for $2 \mathrm{hr}$ at $37^{\circ} \mathrm{C}$ with $180 \mathrm{~nm}$ TeNT-LC and $250 \mathrm{~nm}$ BoNT/A$\mathrm{LC}$, respectively. Leech nerve cord homogenate $(10 \mu \mathrm{g})$ or rat brain homogenate was incubated with the same toxin concentrations in $20 \mu \mathrm{l}$ of standard buffer containing $0.5 \%$ Triton $\mathrm{X}-100$ for $2 \mathrm{hr}$ at $37^{\circ} \mathrm{C}$. Aliquots were analyzed by SDS-PAGE and fluorography or immunoblotting.

Binding assay. GST-syntaxin or GST $(6 \mu \mathrm{g})$ was incubated with $20 \mu \mathrm{g}$ of $\mathrm{His}_{6}-\mathrm{SNAP}-25$ for $1 \mathrm{hr}$ at $4^{\circ} \mathrm{C}$ in a final volume of $30 \mu \mathrm{l}$ with gentle agitation. Binding buffer contained $145 \mathrm{~mm} \mathrm{NaCl}, 25 \mathrm{~mm}$ HEPES-NaOH, $\mathrm{pH} 7.5$, and $0.5 \%$ Triton X-100. Incubation was continued for $1 \mathrm{hr}$ at $4^{\circ} \mathrm{C}$ after adding a $30 \mu \mathrm{l}$ slurry of glutathione-Sepharose (Pharmacia) in binding buffer. After four washes with binding buffer, the matrix was resuspended in a total volume of $60 \mu \mathrm{l}$ of binding buffer. Equal amounts of full-length or TeNT-pretreated $\left[{ }^{35} \mathrm{~S}\right]$-methionine-labeled synaptobrevin were added, and incubation with matrix was continued for $16 \mathrm{hr}$ at $4^{\circ} \mathrm{C}$. The beads were collected by brief centrifugation ( $1 \mathrm{~min}, 6000$ revolutions/min in a microfuge), and supernatants ( $\mathrm{S}$ fraction) were decanted. Pellets were washed four times with $700 \mu \mathrm{l}$ of ice-cold binding buffer and resuspended in a volume ( $\mathrm{P}$ fraction) matching that of the supernatant. Equal portions of supernatant and pellet were subjected to SDS-PAGE, stained, destained, dried, and exposed to film for 2-8 hr.

Cell culture, electrophysiology, and microinjection. Retzius and P-cells were isolated from adult leeches and cultured for synapse formation as described (Bruns et al., 1993). Presynaptic and postsynaptic potentials were recorded with microelectrodes and two conventional bridge amplifiers. Microelectrode (borosilicate glass, Clark Electromedical Instruments, England) resistances ranged from 40 to $60 \mathrm{M} \Omega$. Presynaptic microelectrodes were backfilled with $3 \mathrm{M}$ potassium acetate and $100 \mathrm{~mm}$ $\mathrm{KCl}$. Postsynaptic microelectrode filling solution contained $3 \mathrm{M} \mathrm{KCl}$. Recordings were performed in Leibowitz L-15 medium (Life Technologies, Gaithersburg, MD) supplemented with $3 \mathrm{mM} \mathrm{CaCl}_{2}$. Multiple recordings from the same cell pair were performed as follows: the action potential-evoked postsynaptic signal was measured before (first recording) and $1.5 \mathrm{hr}$ after (second recording) injection. In each recording session the synaptic signal was measured (for $30 \mathrm{~min}$ ) until a stable baseline response was established. At the end of the first recording, toxins were pressure-injected as described below. The increase of the amplitude of the postsynaptic signal seen at the beginning of the recording session (see Fig. 8) is attributable to leakage of high chloride pipette solution into the postsynaptic P-cell. Analysis of the PSP amplitude was restricted to the period when a constant synaptic signal was observed. Experiments were performed on the stage of an inverted microscope (Zeiss Axiovert 100 , Oberkochen, Germany). Electrophysiological data were digitized at a rate of $2 \mathrm{kHz}$, stored on a personal computer, and analyzed with the program AutesP (Garching Instruments, Germany). The injection solution contained recombinant TeNT-LC $(1 \mathrm{mg} / \mathrm{ml})$ or BoNT/A-LC (2.0 $\mathrm{mg} / \mathrm{ml})$ in standard buffer. BoNT/A holotoxin $(0.75 \mathrm{mg} / \mathrm{ml})$-containing solution consisted of $145 \mathrm{~mm} \mathrm{NaCl}, 36 \mathrm{~mm}$ sodium acetate, $5 \mathrm{~mm}$ dithiothreitol (DTT), and $30 \mathrm{~mm}$ HEPES-NaOH, pH 7.0. Saline without toxin was used for control injections. All solutions contained 1\% Fast Green dye (Sigma, St. Louis, MO) to visualize the injection process. Solutions were injected through a separate microelectrode by applying controlled pressure pulses of nitrogen gas (10-20 psi; PLI-100, Medical
Systems, Greenvale, NY). Injection of approximately comparable volumes of control and toxin solution was estimated by visualization of the staining of the cytoplasm. The activity of BoNT/A-LC and DTT-reduced BoNT/A holotoxin in the injection solution was verified at the end of the experiment by test incubations with in vitro translated rat SNAP-25 (see above).

Western blot analysis of individual cultured neurons and protein homogenates. Cultured single Retzius cells or individual Retzius-P-cell pairs carefully were dislodged from the culture dish by aspirating them with a fire-polished glass pipette. This step was visualized on the stage of an invertoscope (Nikon-TMS). The cells were washed once in Ringer's solution containing (in $\mathrm{mM}$ ): $130 \mathrm{NaCl}, 4 \mathrm{KCl}, 1 \mathrm{CaCl}_{2}, 70$ glucose, and 10 HEPES-NaOH, pH 7.3, supplemented with $50 \mu \mathrm{g} / \mathrm{ml}$ bovine serum albumin (BSA), and transferred into a volume of $5 \mu$ l of Ringer's solution (supplemented with BSA). Handling of cells was visualized with a stereo microscope (Nikon-SMZ-1B). Immediately thereafter, SDS-PAGE sample buffer was added, and the samples were boiled. Samples were separated by SDS-PAGE and transferred to nitrocellulose by a semidry electroblotter (Schleicher \& Schuell, Keene, NH). Blots were incubated with affinity-purified antibodies $(1-2 \mathrm{mg} / \mathrm{ml})$ diluted 1:2000 in Trisbuffered saline (20 mM Tris, $\mathrm{pH} 7.4,150 \mathrm{~mm} \mathrm{NaCl}, 8 \%$ powdered nonfat milk, and $0.1 \%$ Tween-20) overnight at $4{ }^{\circ} \mathrm{C}$. Blots were washed and incubated for $1 \mathrm{hr}$ at room temperature with secondary goat anti-rabbit or goat anti-mouse antibodies conjugated to horseradish peroxidase (BioRad, Melville, NY), diluted 1:5000 in Tris-buffered saline (without dry milk). Blots were washed three times, and the immunoreactive bands were visualized with an enhanced chemiluminescence system (SuperSignal Ultra, Pierce, Rockford, IL). The film exposure for Western blots of single cells ranged between 3-8 min.

Quantitation of protein content of single Retzius cells. Groups of five single cultured Retzius cells were washed in Ringer's solution and transferred into an Eppendorf tube. Their protein content was quantified by the NanoOrange Protein Quantitation Kit (Molecular Probes, Eugene, OR) according to the manufacturer's instructions. The average protein content of five Retzius cells was $120 \pm 25 \mathrm{ng}(n=7)$. In calibration tests with BSA, fluorescence intensity was found to increase linearly within a concentration range from 40 to $300 \mathrm{ng}$ protein $/ \mathrm{ml}$. Fluorescence was elicited with $485 \pm 10 \mathrm{~nm}$ excitation and detected with $590 \pm 10 \mathrm{~nm}$ emission with a fluorescence spectrophotometer (Hitachi).

Other methods. SDS-PAGE was performed according to standard procedures (Laemmli, 1970) with the Bio-Rad Protean II minigel system (Richmond, CA). Where indicated, a modification of SDS-PAGE was used that is based on replacing Tris- $\mathrm{Cl}$ with Tricine- $\mathrm{Cl}$, which allows for an improved separation of small peptides (Schägger and von Jagow, 1987). Measurements are given as mean \pm SD, unless indicated otherwise.

\section{RESULTS \\ Leech synaptobrevin and SNAP-25 are homologous to their mammalian counterparts and can be detected in immunoblots of single Retzius cells}

To isolate cDNAs encoding for synaptobrevin and SNAP-25, we screened a $\lambda$-ZAP library prepared from leech nerve cord with a cDNA probe generated by PCR (Saiki et al., 1988), using sets of degenerate oligonucleotide primers (see Materials and Methods). Hybridization-positive clones for synaptobrevin and SNAP-25 were isolated and served for DNA sequencing. The longest synaptobrevin clone contains a short $5^{\prime}$ untranslated region, the coding region, and a $1-\mathrm{kb}$-long $3^{\prime}$ untranslated region (Fig. $1 A$ ). The open reading frame encodes a polypeptide of 169 amino acids with a predicted molecular mass of $17.8 \mathrm{kDa}$ (Fig. $1 B$ ). The $\mathrm{N}$-terminal domain (residues 1-29) shows little homology to synaptobrevin variants of other organisms, whereas the conserved core region of the protein (residues 30-93) is $88 \%$ identical to rat synaptobrevin. The hydrophobic transmembrane anchor (boxed) is followed by a long intravesicular domain. Similar (but not homologous) domains also are found in other invertebrate synaptobrevins such as those of Drosophila and Aplysia, but not in mammalian synaptobrevins (Südhof et al., 1989; DiAntonio et al., 1993; Yamasaki et al., 1994). 
A

\section{B}

GCACGAGCTTTGGTGTTGGTTTTGCAGTCTGCTTATCTGACTTCAATGGCTCAACCACCA
M A Q P P

TGTACAATAGTGTCCGTCATCGATACGACCCGGGGACGCTCGAGGATGGGGTTTGGTTCG TCTGTGCATCCGTTCGCTCGCTCTCCTCCGTTCGTCTGGCGTCGTCTCCCATGTCGCCGC TCGTGCGAAGCTGGCTCGTCGTTCGACTATCGACACCTCCGTTGCCACGGTTCAATTGC GAGTTTTCTTTTTTATTTGAAATAATGCATPCTCTGCTCTTCGTTCCTTATGTGGTGGGA GAGTTTTCTTTTTTATTTGAAATAATGCATTCTCTGCTCTTCGTTCCTTATGTGGTGGGA ACCCTCTCGTCCTTCCGCTTTTCGTCGGCGACCCGGCAGATTTCCCCTTCGACTCACCCT CCGTGTCTTITTCCATGGATTCAGTAGACTATTTGTGTTCCAATCFCTAATACCTGTGTG AAAAGTTCTGGTTCCTTTACTTTGAAAACCGATTTTTAATATTCTACGAGAGTATTACTG CGTTATGCCGTTAGTGCACGAGGGGGAGAGAGGAGAGATAGAGAGAGAGAAAGAGGTGA ATGAAAGAAAGTTAAAAGTAGATTTATTGAAATTTATCTTTTCTTCTTTGTGTCCGAGGT AGTTTTTTGAGACTAGGAGCTCGTCGTGGAGGGTTTGACCTGGAGCCATCTGAGTTACTT GACTTTTTTCTCTCTGTTGATTTTCATTGTCAATGTTGTTTTAGAGTGTCTAGGAGCTGA CGATGTCGTGCATGTGCATGTATGTGTGTGTGTGTTTCACATTCTTCCATTCCTTCCTTC TATATTCTGCGTGGTGGAGACGATCGGCCTCGTGCC

Hirudo Rat 2 Rat 1 Torpedo Loligo Drosophila Aplysia

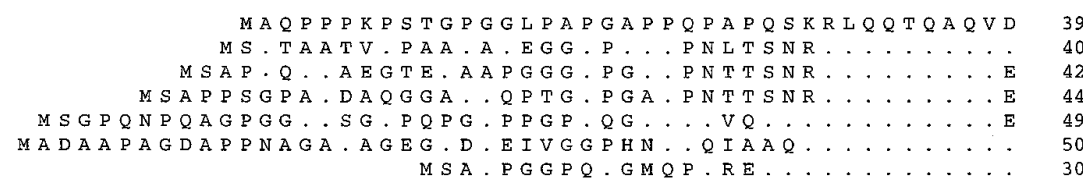

Hirudo

Rat 2

Rat 1

Torpedo

Loligo

Drosophila

Aplysia

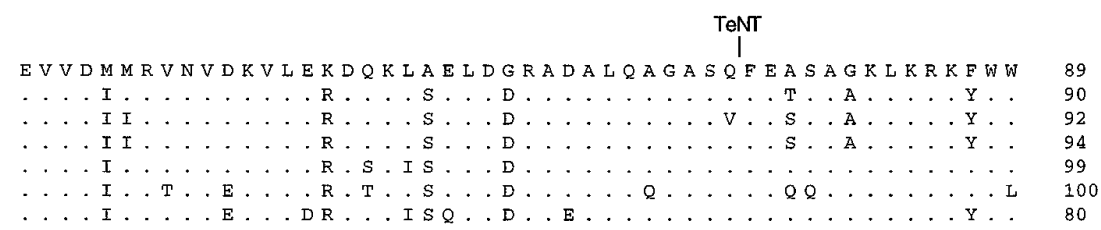

\begin{tabular}{|c|c|c|c|}
\hline $\mathrm{N} \mathrm{M}$ & MMLIM & 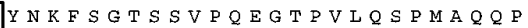 & \\
\hline L & . I . L . VI C.IIII. I IVYF & $S T$ & \\
\hline . $\mathrm{C}$ & . . IML.. I C.II.. VIVIY. & F T & \\
\hline . $\mathrm{C}$ & . . I M L. GIG. I I. IVIIIYF & $F T$ & 120 \\
\hline . $\mathrm{C}$ & $\cdot I \cdot T V I I V \cdot A$ & A T & 125 \\
\hline Q. I. & . I. . VIGI... G I I N K L & G I I G GEQP PQY. Y P PQYM. P.P P & 150 \\
\hline . $\mathrm{C}$ & $\ldots I \ldots I I G . I . I . I I V$ & VTSQDSG & \\
\hline
\end{tabular}

QSLPENIP PASPVGGGGGGKKGKNKQPHSS

Hirudo

Rat 2

Torpedo

Torpedo

Loligo

Aplysia

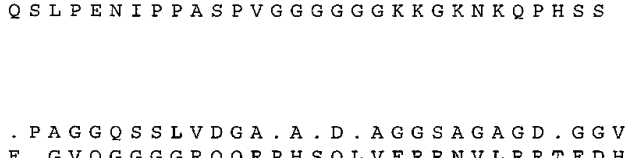

E. GVQGGGGRQQRPHSQLVERRNVLRRTEDHIGCRPHIHSFIHIFMICEV
Figure 1. Structure of Hirudo synaptobrevin. A, cDNA and deduced amino acid sequences of Hirudo synaptobrevin. The translated amino acid sequence is shown in single letter code below the nucleotide sequence. The transmembrane domain is underlined, and the asterisk that follows the amino acid sequence denotes the stop codon. $B$, Sequence comparison of various isoforms of synaptobrevin. Sequences are taken from the following references: rat (Elferink et al., 1989), Torpedo (Trimble at al., 1988), Loligo (Hunt et al., 1994), Drosophila (DiAntonio et al., 1993), and Aplysia (Yamasaki et al., 1994). The TeNT cleavage site of rat synaptobrevin is marked. The putative transmembrane domain is boxed. Dots indicate amino acids that are identical to Hirudo synaptobrevin. Hirudo synaptobrevin has an extended intravesicular domain similar (but not homologous) to isoforms of Drosophila and Aplysia. 
The longest SNAP-25 clone had a length of $1.4 \mathrm{~kb}$ (Fig. $2 A$ ). This cDNA encodes a 212-amino-acid protein with a deduced molecular mass of $23.8 \mathrm{kDa}$. The putative initiation site is preceded by three in-frame stop codons, suggesting that the cDNA comprises the entire translated region. Comparison of the leech and the rat protein reveals $51 \%$ identity and $75 \%$ similarity (Fig. $2 B$ ). Leech SNAP-25 has a cluster of three cysteine residues in the middle of the protein. The regions of highest homology reside in the N-terminal half and the C-terminal third of leech SNAP-25 and coincide with the domains of rat SNAP-25, which are essential for binding to syntaxin (residues 21-100) and to synaptobrevin (residues 180-206, numbering as in rat SNAP-25; Chapman et al., 1994; Hayashi et al., 1994).

To identify native leech synaptobrevin and SNAP-25, we produced antisera using recombinant protein fragments as antigens. For synaptobrevin, a C-terminal fragment comprising the entire intravesicular domain (amino acid positions 114-169) was used. For SNAP-25, antibodies were raised against the C-terminal half of the protein (amino acid positions 112-212). The resulting antisera were affinity-purified (see Materials and Methods) and tested by immunoblotting on leech nerve cord homogenate. The synaptobrevin antibody (R37) specifically recognizes a polypeptide that migrates at a position corresponding to an apparent molecular mass of $\sim 21 \mathrm{kDa}$ (Fig. $3 A$ ). As expected, this position is higher than that of mammalian synaptobrevin but resembles that observed for the similar-sized synaptobrevin isoforms in Drosophila or Aplysia (Yamasaki et al., 1994; Sweeney et al., 1995). The SNAP-25 antibody (R50) identifies a protein that has an apparent molecular mass of $\sim 29 \mathrm{kDa}$, also slightly larger than the mammalian variants (Fig. $3 A$ ). The same band also reacted with a monoclonal antibody $(\mathrm{Cl} 71.1)$ that was raised against rat SNAP-25 (data not shown) and recognizes a highly conserved domain (amino acids 20-40 of rat SNAP-25; compare in Fig. 2). Furthermore, we translated leech synaptobrevin and SNAP-25 in vitro in the presence of $\left[{ }^{35} \mathrm{~S}\right]$-methionine and found the radiolabeled proteins to comigrate with their corresponding immunoreactive bands from nerve cord homogenate (Fig. 3B).

Retzius cells that serve as presynaptic neurons in our experiments are large (diameters of $60-80 \mu \mathrm{m}$ ) and can be manipulated individually by fire-polished glass pipettes. Using a highly sensitive protein quantitation assay, we determined that a single Retzius cell contains, on average, $24 \pm 5 \mathrm{ng}$ of total protein $(n=7$; see Materials and Methods). We therefore asked whether synaptobrevin and SNAP-25 are detectable by immunoblotting of a single Retzius cell. As shown in Figure $3 C$, Western blots of a single Retzius cell display immunoreactive bands for both proteins. The intensity of the immunoreactive bands was approximately proportional to the number of neurons transferred to a gel lane. These findings provide the possibility to study the proteolytic activity of neurotoxins with biochemical techniques in individual Retzius-Pcell pairs after physiological recordings.

\section{Sensitivity of leech synaptobrevin to tetanus toxin}

Native and recombinant forms of leech synaptobrevin were used to study the effect of tetanus neurotoxin. TeNT-LC cleaves rat synaptobrevin II between Gln 76 and Phe 77 (numbering as in rat synaptobrevin; Link et al., 1992; Schiavo et al., 1992), a region that is highly conserved in the leech protein. Incubation of leech nerve cord homogenate with TeNT-LC resulted in a strong reduction of synaptobrevin immunoreactivity (Fig. $4 A$ ). In parallel, an immunoreactive band of lower molecular mass $\left(M_{\mathrm{r}}\right.$ approximately equal to 15,000$)$ appeared. This band was not seen in mock incubations containing toxin but no homogenate (data not shown). The 15 $\mathrm{kDa}$ band corresponds to a C-terminal cleavage product of synaptobrevin, because the detecting antibody was raised against the intravesicular domain of the protein. TeNT-LC also cleaved recombinant synaptobrevin that was translated in vitro in the presence of $\left[{ }^{35} \mathrm{~S}\right]$-methionine, generating two radiolabeled fragments, a 15 and a $7 \mathrm{kDa}$ fragment (Fig. $4 C$ ). The $15 \mathrm{kDa}$ fragment closely resembles the $\mathrm{C}$-terminal cleavage product that was seen in TeNT-treated homogenate. The $7 \mathrm{kDa}$ band therefore represents the corresponding N-terminal fragment of the protein.

Previous studies have shown that rat synaptobrevin I is less sensitive in vitro to TeNT cleavage than rat synaptobrevin II. The reduced cleavability of the synaptobrevin I isoform is attributable to substitution of a glutamine residue with a valine residue at the cleavage site (Schiavo et al., 1992) (see also Fig. 1B). When the corresponding point mutation was introduced into leech synaptobrevin (replacement of Gln75 with Val), cleavage was less efficient than in the wild-type protein (Fig. 4B). Taken together, these results suggest that leech synaptobrevin is cleaved efficiently by tetanus toxin and that proteolysis occurs at a site which corresponds to that identified in the mammalian isoform.

\section{Do TeNT-LC cleavage products of synaptobrevin participate in complex formation with syntaxin and SNAP-25?}

Synaptobrevin, SNAP-25, and syntaxin form, in vitro, a stable ternary complex (SNARE complex) that has been implicated in the fusion of synaptic vesicles with the plasma membrane (Söllner at al., 1993b). In the following experiment, we investigated whether a similar complex forms between the Hirudo isoforms of these proteins and studied further whether the fragments of proteolyzed synaptobrevin are able to participate in complex formation. Leech GST-syntaxin, immobilized on glutathioneSepharose beads, was saturated with $\mathrm{His}_{6}-\mathrm{SNAP}-25$, resulting in a stable binary complex (Fig. $5 A$; see also Hayashi et al., 1994). Full-length $\left[{ }^{35} \mathrm{~S}\right]$-methionine-labeled synaptobrevin was prepared by in vitro translation and incubated with the preformed syntaxin/ SNAP-25 complex. Binding was analyzed by SDS-PAGE and fluorography after separation of beads $(P)$ from unbound material $(S)$. Full-length synaptobrevin efficiently bound to the immobilized complex of GST-syntaxin and SNAP-25, but not to control beads (Fig. $5 B$ ), demonstrating that, like their mammalian counterparts, the leech proteins form a stable ternary complex. TeNTLC-treated synaptobrevin was tested for binding with the same procedure. The N-terminal cleavage product bound to the binary complex, whereas the $\mathrm{C}$-terminal fragment remained in the supernatant. Similarly, no binding of the C-terminal fragment was observed when TeNT-treated nerve cord homogenate instead of recombinant synaptobrevin was used (data not shown). Taken together, our findings demonstrate that the vesicle membraneanchored part of synaptobrevin released by TeNT fails to participate in ternary complex formation.

\section{Leech SNAP-25 is resistant to cleavage by BoNT/A}

To test whether leech SNAP-25 is susceptible to cleavage by BoNT/A, we incubated nerve cord homogenate with recombinant BoNT/A-LC. Incubation neither led to a reduction in the intensity of the SNAP-25 signal nor caused the generation of any proteolytic fragment (Fig. 6A). Similarly, recombinant SNAP-25 protein generated by in vitro translation was resistant to proteolysis by BoNT/A-LC (Fig. 7). Parallel incubation of rat brain homogenate with BoNT/A-LC shows that the mammalian isoform is cleaved 
A

1 GAGATCAACTCTGACAGCTGCAAAGCATTTGACCCTTGACCTAATTACTGAGCTTTTGGA 61 TTACAATAAAGGTCGTGGACATCGACCAACACCCTTCGAGAAAATAAGGTCACCTTTGGG

121 GCACATCCTTCAGCGGAAAGTTCTGGAACGAGCGGGATGGCCAAGGATATCAAGCCCAAG

181 CCTGCCAATGGGAGAGACTCACCGACTGATCTCCAGGAGATTCAACTCCAGATGAACGCC

$9 \quad \begin{array}{lllllllllllllllllllllll}9 & \text { P } & \text { A } & \text { N } & G & \text { R } & D & S & P & \text { T } & \text { D } & \text { L } & Q & \text { E } & \text { I } & Q & L & Q & M & N & A\end{array}$

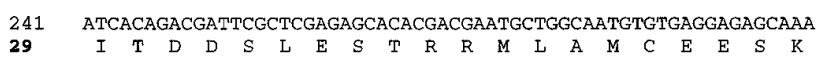

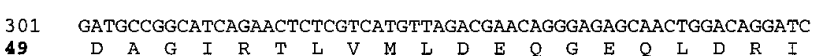

361 GAGGAGGGCATGGATCAGATCAACCAGGACATGAGGGACGCCGAAAAAAACCTGGAAGGG

$\begin{array}{lllllllllllllllllllll}69 & E & E & G & M & D & Q & I & N & Q & D & M & R & D & A & E & K & N & L & E & G\end{array}$

421 ATGGAAAAGTGTTGCGGTCTCTGCATCCTCCCATGGAAGAGGACGAAAAACTTCGACAAG

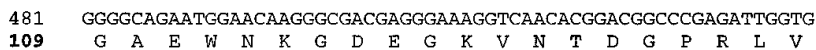

541 GTCGGTGATGGGAACATGGGACCATCCGGAGGATTCATTACCAAGATAACGAACGACGCA

129 V G D G

601 CGAGAGGAGGAGATGGAGCAGAACATGGGCGAGGTGAGCAACATGATCAGCAACCTGAGG

$149 \quad \begin{array}{llllllllllllllllllll}R & E & E & E & M & E & Q & N & M & G & E & V & S & N & M & I & S & N & L & R\end{array}$

661 AACATGGCCGTCGACATGGGTAGCGAAATTGACTCCCAGAACAGACAAGTCGATAGAATC

169 N $\begin{array}{llllllllllllllllllll} & \text { M } & A & V & D & M & G & S & E & I & D & S & Q & N & R & Q & V & D & R & I\end{array}$

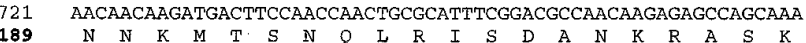

781 CTCCTGAAAGAATAATCGGACGCCCTGGCGACAAGCGGCGCGACAAGCAGCGACAAGCA

209 L

841 CGACAAAATCAAGCGATGTGGTGTCGTGTATTTTCGAGAAATTCTTTTTCAATCTTTCAA TTG TGGAACCCCAGTGACGTCACTTTCTGTTATATTTTTAGTAGCAACGTCGCCCACCCTCAC TCACCCTTACCCCGTCCTCACCCCCTCACCCCCCCTCATCATCCCTCACCTCACCCTCAC CCCGTCCTCACCATCCCTCATCCCGTCATCCTGTCCTCGTTCGAATCCTAGCTTTCGATC 41 CTCCCTTCCGAAACTCGATGTCTTTTTTTGTTTCACTTTCAGTCGTCTTAGAGCGAATAA 1261 CCTTTTTTTTTCGAAATTATGGATTTTAATTTCTTCTCGTGCC

B

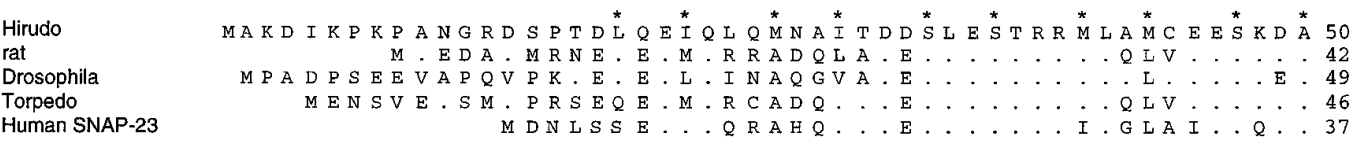

Hirudo

Drosophila

Torpedo

Human SNAP-23

Hirudo

rat

Drosophila

Torpedo

Human SNAP-23

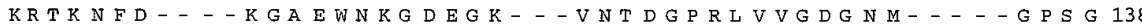

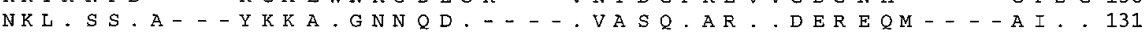

NKSQS.RE- - DDGT.KGN.D...-.VNNQ.QR.MD.R.GM - - MAQA 139

NKL. . EAGGAYKKV:GNNQD.....VASQ:AR:MD:REQM - . AM. 138

N.... ESGKAYKTT.GD.G.NSPCN.VSKQ.GP.TNGQLQQPTTGAV. . 137

Figure 2. Structure of Hirudo SNAP-25. A, cDNA and deduced amino acid sequences of Hirudo SNAP-25. The translated amino acid sequence is shown in single letter code below the nucleotide sequence. The designated initiator methionine is preceded by three in-frame stop codons, but no other methionine codon, in the untranslated region. B, Sequence comparison of various isoforms of SNAP-25. The sequence of rat SNAP-25 was provided by T. C. Südhof and is identical to the mouse SNAP-25 sequence (Oyler et al., 1989). Other sequences are taken from the following references: Drosophila and Torpedo (Risinger et al., 1993) and Human SNAP-23 (Ravichandran et al., 1996). Figure legend continues. 
Figure 3. Characterization of native and recombinant leech synaptobrevin and SNAP-25. $A$, Immunoblots of leech nerve cord homogenate were probed with affinity-purified polyclonal antibodies raised against leech synaptobrevin and SNAP-25. Each lane is an immunoblot of total homogenate $(5 \mu \mathrm{g}$ of protein/lane) separated on a $14 \%$ SDS-polyacrylamide gel. Immunoreactive proteins were visualized with horseradish peroxidase-coupled secondary antibody and an enhanced chemiluminescent system (SuperSignal, Pierce). $B$, Full-length leech synaptobrevin and SNAP-25 were generated by in vitro transcription-translation in the presence of $\left[{ }^{35} \mathrm{~S}\right]$-methionine (and microsomes for synaptobrevin). The major translation products comigrate with the corresponding immunoreactive band from nerve cord homogenate. Note that native leech SNAP-25 has a slightly lower mobility than the recombinant protein, probably because of palmitoylation of the native protein (Veit et al., 1996). C, Immunoblot analysis of single Retzius cells. Samples containing the indicated number of Retzius cells were separated on a $15 \%$ SDS-polyacrylamide gel and immunoblotted. The blot was stained simultaneously with antisynaptobrevin and anti-SNAP-25 antibodies. Immunoreactive proteins were visualized as described above.
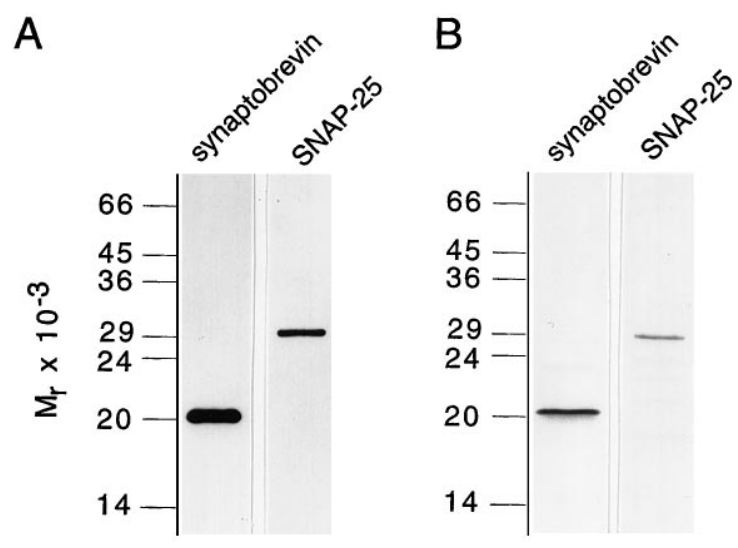

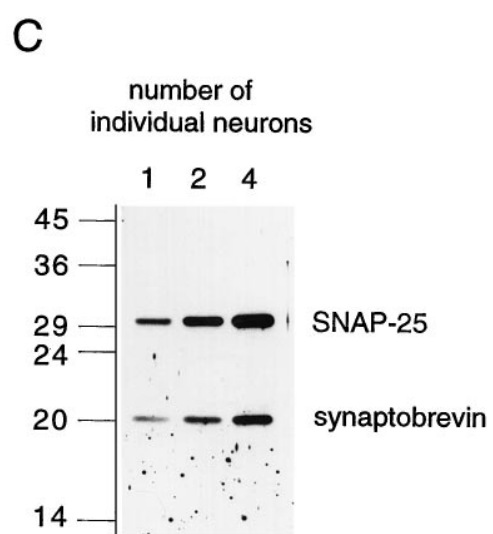

and confirms the activity of the toxin used in our experiments (Fig. $6 B$ ). Furthermore, dithiothreitol (DTT)-reduced BoNT/A holotoxin also failed to cleave leech SNAP-25 (data not shown). These findings indicate that the leech isoform is insensitive to BoNT/A proteolysis. This result was unexpected in light of the high degree of sequence conservation and prompted us to investigate the structural features that render the protein resistant to toxin cleavage. Sequence comparison between leech SNAP-25 and the rat isoform reveals that the leech protein contains a lysine (residue 204) instead of a glutamine as the N-terminal amino acid of the scissile bond (Fig. $2 B$ ). However, substitution of this lysine with a glutamine residue (mutant $\mathrm{m} 1$ ) failed to make the protein susceptible to proteolysis by BoNT/A-LC (Fig. 7). To resolve whether amino acid differences in the $\mathrm{N}$ - or C-terminal part of leech SNAP-25 are responsible for this toxin resistance, we replaced the C-terminal 40 residues of leech SNAP-25 with the homologous domain from rat SNAP-25. This chimeric protein (m2) was fully cleaved by BoNT/A-LC. We then successively shortened the rat sequence in the chimera by replacing it with the corresponding leech sequences (m3-m6). Restoring the leech sequence to within nine amino acids on the N-terminal side of the cleavage site did not interfere with proteolysis (m3 and m4, Fig. 7). Further extension of the leech sequence reduced (m5) and abolished (m6) cleavage. This demonstrates that the region $\mathrm{N}$-terminal of the cleavage site encompassing residues 196-204 is critical for cleavage. Indeed, direct replacement of this domain in the leech wild-type protein with the corresponding rat domain (comprising 5 amino acid exchanges between leech and rat) renders the leech protein (m7) susceptible to BoNT/A-LC cleavage. However, a comparison of the cleavage of mutants $\mathrm{m} 1$ and $\mathrm{m} 5$ suggests that residue 204 and those C-terminal to the cleavage site are also sufficient to allow partial cleavage. In agreement with this observation, exchange of amino acids 196-209 with those of the rat protein improved cleavability of $\mathrm{m} 8$, as compared with $\mathrm{m} 7$. Taken together, the results indicate that amino acids on both sides of the cleavage site, in addition to those at the scissile bond itself, are responsible for the toxin resistance of leech SNAP-25.

\section{The effect of TeNT-LC and BoNT/A-LC on neurotransmitter release correlates with the toxin- mediated proteolysis in the presynaptic neuron}

Having shown that leech synaptobrevin is cleaved by TeNT-LC but that leech SNAP-25 is resistant to BoNT/A-LC proteolysis, we next investigated the action of the toxins on transmitter release in the Retzius $\rightarrow \mathrm{P}$-cell synapse in culture (Fig. 8A). Serotonin (5hydroxytryptamine, 5-HT) release was evoked by stimulation of single action potentials in the presynaptic Retzius cell (Fig. 8B,D, top panels). In postsynaptic P-cells, activation of the 5-HT-induced chloride conductance (Drapeau and Sanchez-Armass, 1988) was recorded as a depolarization of the membrane potential, because the postsynaptic microelectrode contained a high $\mathrm{Cl}^{-}$concentration solution (Fig. 8B,D, bottom panels). As illustrated in Figure $8 C$, injection of TeNT-LC into the soma of the Retzius cell produced a strong and irreversible block of synaptic transmission.

Dots indicate amino acids that are identical to Hirudo SNAP-25. Gaps (bars) were introduced to improve the alignment. Vertical bars mark the clustered cysteine residues. Hirudo SNAP-25 has a cluster of three cysteine residues at the amino acid positions 92, 93, and 96. An additional cysteine residue in the leech sequence occurs at amino acid position 44 and also is found in Drosophila SNAP-25. The BoNT/A cleavage site of rat SNAP-25 is marked. The amphipathic character of the putative $\alpha$-helical regions implicated in syntaxin and synaptobrevin binding (Chapman et al., 1994; Hayashi et al., 1994) is well preserved in all variants. The residues forming its hydrophobic face are marked by asterisks. 
A

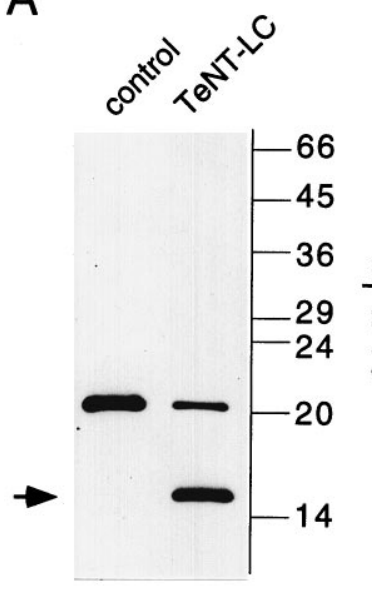

B

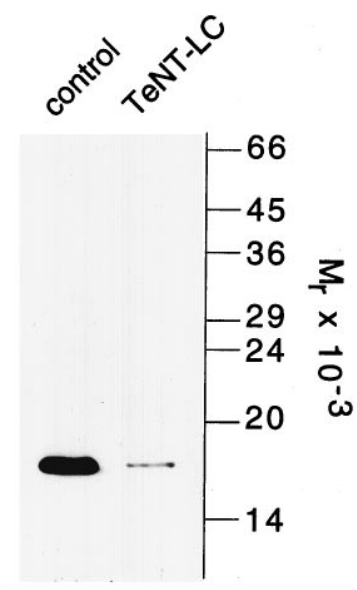

C

\section{wildtype Gln75Val}

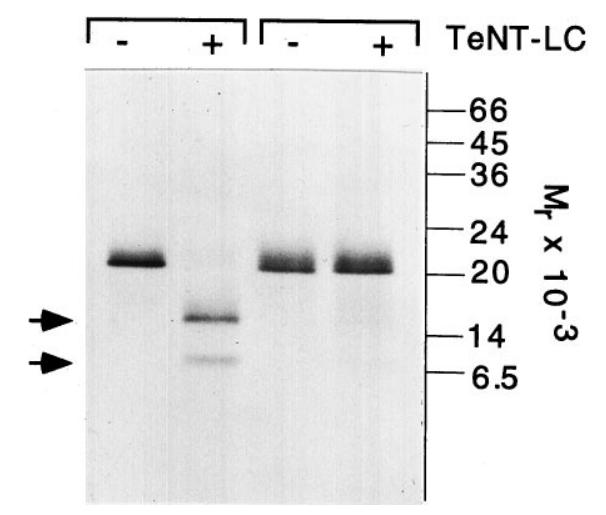

Figure 4. Leech synaptobrevin is sensitive to TeNT-LC cleavage. A, Leech nerve cord homogenate was incubated in the absence (control) or in the presence of $180 \mathrm{~nm} \mathrm{TeNT-LC}$ for $2 \mathrm{hr}$ at $37^{\circ} \mathrm{C}$. Samples $(5 \mu \mathrm{g}$ of protein/lane) were analyzed by SDS-PAGE (15\% gel) and immunoblotting as described in Figure 3. TeNT cleavage of synaptobrevin generates a breakdown product (arrow) that reflects a C-terminal fragment of synaptobrevin. B, Incubation of TeNT-LC with rat brain homogenate (LP2 fraction, $5 \mu \mathrm{g}$ protein/lane) leads to a reduction of synaptobrevin II immunoreactivity. Synaptobrevin II was visualized with the monoclonal antibody $\mathrm{Cl}$ 69.1. $C$, Recombinant leech synaptobrevin generated by in vitro transcription-translation is cleaved by TeNT-LC, resulting in radiolabeled fragments of $7 \mathrm{kDa}(\mathrm{N}$ terminal) and $15 \mathrm{kDa}(\mathrm{C}$ terminal). Amino acid exchange of Gln75 with Val reduced cleavability of the mutant $\left(\mathrm{m}_{\mathrm{Gln} 75 \mathrm{Val}}\right)$. Samples were separated on a $15 \%$ SDS-polyacrylamide gel and analyzed by fluorography.

In contrast, injection of comparable volumes of control solution had no effect on the synaptic signal (see Fig. 9A). These results agree well with our previous observation showing that exocytosis of serotonergic vesicles, monitored by carbon fiber amperometry, is inhibited when TeNT-LC is injected into isolated Retzius cells (Bruns and Jahn, 1995). The delay between toxin injection and a $50 \%$ inhibition of the synaptic signal varied between 10 and 25 $\min (n=8)$. Short delays were observed in Retzius cells that had a relatively short axon stump, suggesting that the time course of inhibition is determined mainly by the rate of toxin diffusion. Furthermore, we reanalyzed synaptic transmission in the same cell pair $3 \mathrm{~d}$ after injection to examine whether transmitter release recovers from poisoning after extended culturing times. Whereas neurons injected with control solution showed clear and often unchanged synaptic transmission, no recovery of the synaptic signal was observed in TeNT-LC-injected cells (data not shown). The longlasting block may be attributable to enduring toxin action but also may reflect the slow resynthesis of synaptobrevin, as suggested by experiments in chromaffin cells (Bartels et al., 1994).

The experiments of Blasi et al. (1993a) with rat brain synaptosomes suggested that SNAP-25 is the sole substrate of BoNT/A. The identification of a toxin-resistant SNAP-25 isoform in Hirudo provides the unique opportunity to study the effect of BoNT/A poisoning in a preparation equipped with a toxin-resistant target protein. In fact, injection of this toxin into Retzius cells produced no alteration of transmitter release (Fig. $8 D, E, n=5$ ), even if the LC-concentration was more than fivefold higher $(7 \mathrm{mg} / \mathrm{ml})$ than the highest TeNT-LC concentration used. Because experiments in Aplysia neurons suggested that BoNT/A-LC requires the presence of the heavy chain for activity (Maisey et al., 1988; Poulain et al., 1990), we also injected reduced holotoxin, which should have free LCs and HCs. Again, no impairment of the synaptic signal was observed (see Fig. 9A, $n=5$ ). The activity of BoNT/A-LC and of reduced $\mathrm{BoNT} / \mathrm{A}$ holotoxin in the injection solution was verified at the end of the experiment by test incubations with in vitro translated rat SNAP-25 (data not shown). Therefore, the lack of sensitivity of the release process toward BoNT/A is consistent with the resistance of leech SNAP-25 to toxin-mediated cleavage in vitro.

To study the proteolytic activity of the toxins directly in the functioning neuron, we subjected individual Retzius-P-cell pairs, which had been analyzed for transmitter release, to immunoblotting. In each cell pair, synaptic signals were recorded before and $1.5 \mathrm{hr}$ after toxin injection. At the end of the second recording, the cell pair was dislodged carefully from the culture dish and transferred into a small volume of Ringer's solution. The toxin was inactivated by immediate addition of SDS-PAGE sample buffer and boiling. This protocol facilitated the direct comparison of physiological and biochemical results obtained from control and toxin-injected neurons. As observed under continuous recording conditions, the amplitude of the synaptic signal was strongly reduced after TeNT-LC injection into Retzius cells, whereas it remained unchanged when neurons were injected with BoNT/ A-LC or control solution (Fig. 9A). The corresponding immunoblots of single-cell pairs were stained simultaneously with SNAP-25 and synaptobrevin antibodies (Fig. 9B,C). This allowed us to use one of the immunostained proteins as an internal standard to correct for possible differences in the size of individual cell pairs. As shown in Figure 9B, synaptobrevin immunoreactivity is strongly diminished in TeNT-LC-injected pairs, as compared with controls. Thus, in the intact neuron, most of synaptobrevin is accessible to the toxin and seems to be cleaved in $<2 \mathrm{hr}$. A proteolytic fragment was detected in all poisoned neurons, with a size closely resembling that observed after in vitro proteolysis of leech synaptobrevin (Fig. 4B). These results demonstrate that the block of transmitter release by TeNT-LC is accompanied by cleavage of synaptobrevin in the presynaptic neuron. The small residual signal reflecting intact synaptobrevin is most likely caused by synaptobrevin in the uninjected postsynaptic P-cell. In contrast, SNAP-25 immunoreactivity was not changed in BoNT/A-LCinjected pairs (Fig. 9C). Together, these results provide a direct correlation between the block of exocytosis and the ability of the neurotoxin to proteolyze its target protein in a single neuron. 
Figure 5. Effect of TeNT-LC treatment of synaptobrevin on its ability to assemble with syntaxin/SNAP-25 complexes. Leech GST-syntaxin was saturated with $\mathrm{His}_{6}-$ SNAP-25 and immobilized on glutathione-Sepharose beads. Glutathione $S$-transferase (GST) served as control. Radiolabeled synaptobrevin was generated by in vitro translation and incubated with $300 \mathrm{~nm}$ TeNT-LC $(+)$ or control buffer $(-)$. Full-length protein or toxin-generated fragments were incubated overnight with preformed $G S T$ syntaxin/SNAP-25 complexes. Beads and supernatants were separated by centrifugation, the pellets were washed, and equal fractions of the supernatants $(S)$ and pellets $(P)$ were analyzed. $A$, Coomassie blue-stained gel (SDSPAGE, $13 \%)$ of pellets $(P)$ and supernatants $(S)$. $\mathrm{His}_{6}-$ SNAP-25 forms a stable complex with GST-syntaxin but does not bind to control beads. $B$, Fluorography of the $P$ and $S$ fractions separated on a Tricine-SDS polyacrylamide gel. Full-length synaptobrevin efficiently binds to GST-syntaxin/SNAP-25 complexes. The faster-migrating $\mathrm{N}$-terminal cleavage product, but not the C-terminal fragment, participates in ternary complex formation.

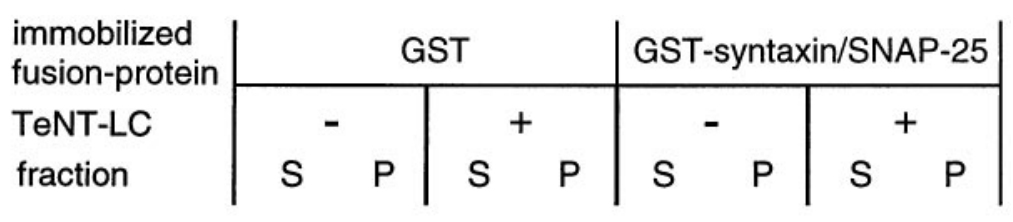

A

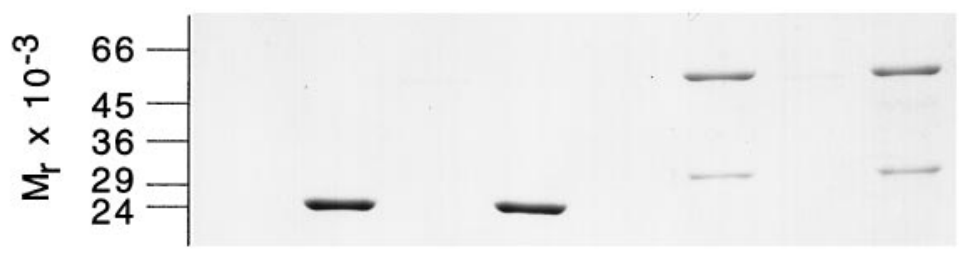

B

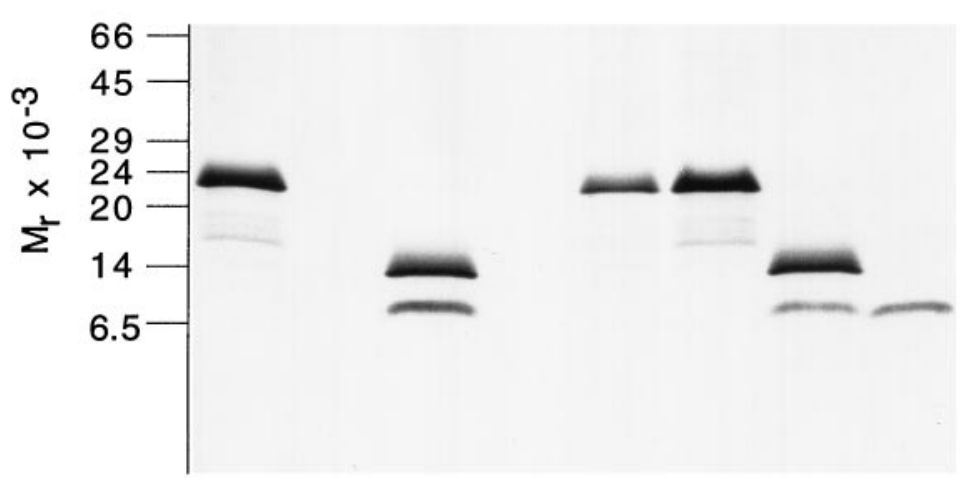

A
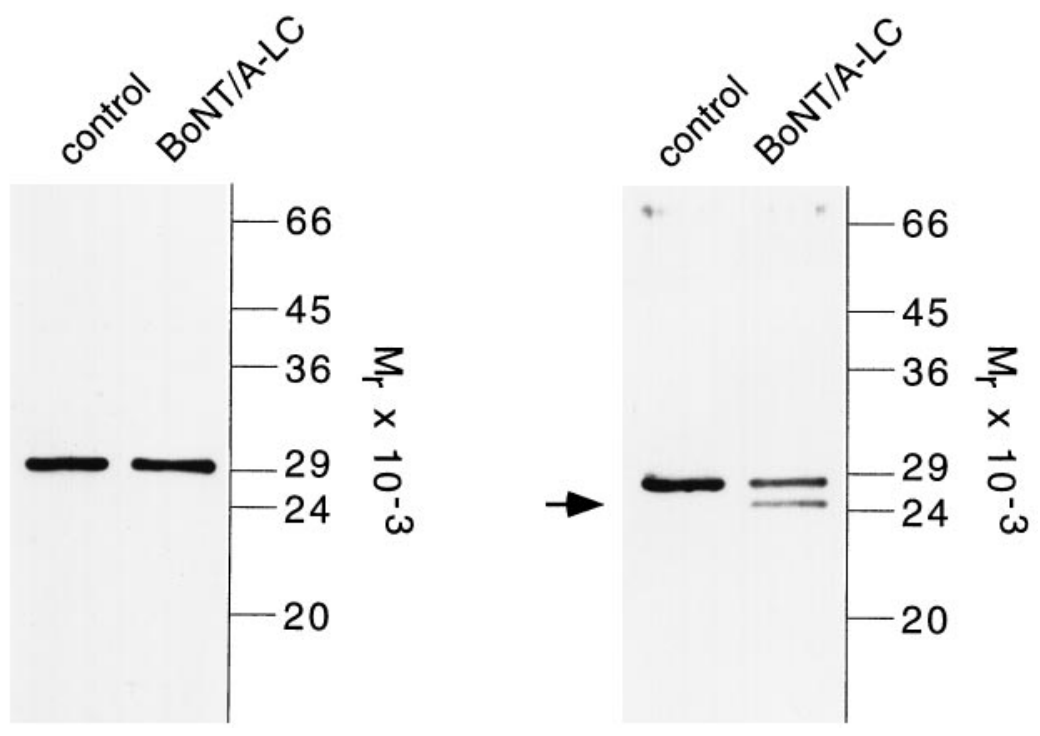

et al., 1989; Archer et al., 1990; DiAntonio et al., 1993; Hunt et al., 1994; Yamasaki et al., 1994), including conservation of the toxin cleavage site. Like its mammalian homolog (Söllner et al., 1993b; Hayashi et al., 1994) Hirudo synaptobrevin is able to form a stable ternary complex with the leech isoforms of SNAP-25 and syntaxin. Thus not only the primary structure but also the biochemical properties of the proteins are conserved during evolution.

TeNT inhibits transmitter release from neurons in widely divergent species (Mochida et al., 1989; Llinás et al., 1993; Hunt et al., 1994), blocking exocytosis of both small and large dense core vesicles (Bruns and Jahn, 1995). However, it is still unclear how

toxin cleavage of synaptobrevin causes inhibition of exocytosis,
Leech synaptobrevin is highly homologous to isoforms from

other invertebrates and vertebrates (Elferink et al., 1989; Südhof
In this study we investigated the effects of tetanus toxin and botulinus toxin A on synaptic transmission and combined physiproteolytic activity of the toxins in the intact neuron. Our results provide a direct correlation between the block of exocytosis and the effect of the neurotoxin L-chains on their target proteins in vivo. Furthermore, they demonstrate the versatility of the Retzius $\rightarrow$ P-cell synapse as model for the study of transmitter release at the single-cell level. 
control BoNT/A-LC

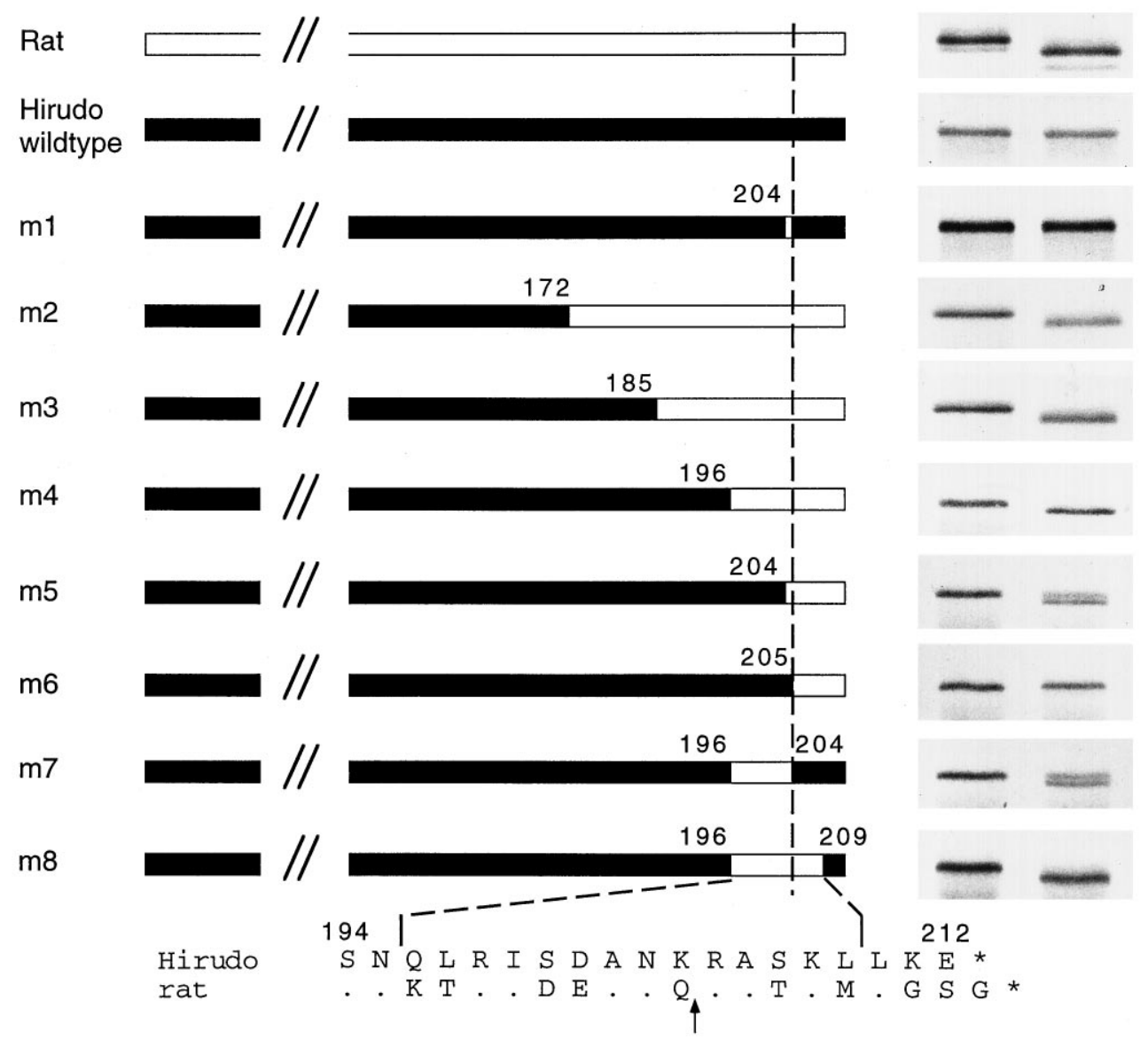

Figure 7. Structural features that protect leech SNAP-25 from BoNT/A proteolysis. The scheme illustrates a mutant containing a single amino acid substitution ( $\mathrm{m} 1)$ and the chimeras formed between leech SNAP-25 (black) and rat SNAP-25 (white, $m 2-m 8$ ). Proteins were radiolabeled by in vitro transcription-translation in the presence of $\left[{ }^{35} \mathrm{~S}\right]-$ methionine. Wild-type and mutated proteins were incubated in the absence (control) or in the presence of $500 \mathrm{nM} \mathrm{BoNT/A}-L C\left(2 \mathrm{hr}\right.$ at $\left.37^{\circ} \mathrm{C}\right)$. Samples were analyzed by SDS-PAGE and fluorography. Numbers indicate the position of the first and last amino acids of the domain that are exchanged between the leech and the rat protein (numbering refers to leech SNAP-25). A sequence comparison of the C-terminal domain of both proteins is shown at the bottom of the figure. Dots indicate the amino acids that are identical to Hirudo SNAP-25. Leech SNAP-25 became sensitive to BoNT/ A-LC cleavage when the residues 196, 197, 200, 201, and 204 were replaced with those of the rat protein $(m 7)$. Additional substitution of residues 207 and 209 with the corresponding residues of the rat protein improved the cleavability $(m 8)$. The BoNT/A cleavage site of rat SNAP-25 is indicated by the arrow and the dashed line. i.e., whether the proteolytic loss of a functional domain or the generation of a toxic breakdown product is primarily responsible for the block. No synaptobrevin fragments were detected when intact neurons or synaptosomes were poisoned (Link et al., 1992; Mundigl et al., 1995; Osen-Sand et al., 1996; Williamson et al., 1996). In these studies, antibodies binding N-terminal of the cleavage site were used for detection. Like other invertebrate isoforms, leech synaptobrevin contains an extended intravesicular domain that provides a convenient epitope for immunodetection of C-terminal fragments. Injection of TeNT-LC into Retzius cells revealed that depletion of intact synaptobrevin was paralleled with the appearance of a C-terminal cleavage product that equalled in size the C-terminal fragment obtained by in vitro cleavage. This suggests that cleavage in the intact neuron occurs at the same site as in vitro and further demonstrates that the C-terminal fragment persists after poisoning (Fig. 4). In addition, we found that most of the intracellular synaptobrevin pool is accessible to toxin, suggesting that poisoned neurons contain mainly synaptic vesicles equipped with the truncated protein.

Recently, it has been suggested that the v-SNARE synaptobrevin serves as a "pilot" protein, which targets the vesicle to the plasma membrane, and that the specific pairing between the cytoplasmic domains of v- and t-SNAREs mediates docking of the vesicle before exocytosis (Rothman and Wieland, 1996). However, previous morphological work demonstrated that docking of synaptic vesicles is not impaired, but rather increased, in TeNT-poisoned squid terminals (Hunt et al., 1994). Thus, the detection of a membrane-anchored synaptobrevin fragment in the poisoned Retzius cell poses the question of whether its remaining cytoplasmic domain still may interact with syntaxin and SNAP-25. This question has been difficult to address with the mammalian isoforms of these proteins because of the relatively small size of the corresponding cleavage product of rat synaptobrevin. After TeNT-LC cleavage, the N-terminal fragment of leech synaptobrevin, but not its C-terminal fragment, bound to SNAP-25/syntaxin complexes in vitro. Thus, it is unlikely that a direct interaction of the membrane-anchored synaptobrevin fragment with syntaxin and SNAP-25 can provide the structural basis for vesicle docking after TeNT cleavage. Our results also agree with the observation of Niemann and coworkers (1994) showing that the complexforming domain of synaptobrevin seems to be confined to the $\mathrm{N}$-terminal region of the protein comprising the residues 37-70 (numbering as in rat synaptobrevin; Hayashi et al., 1994). However, immunoprecipitation experiments with rat brain detergent extracts revealed that the C-terminal cleavage product of synaptobrevin still is associated with the 20S complex that includes recombinant $\alpha$-SNAP and NSF (Pelligrini et al., 1995). Together, these findings indicate that a proteolytic loss of a functional domain of synaptobrevin becomes apparent for protein interactions in the ternary "core" complex but may be altered by additional binding of cytosolic factors, such as NSF and SNAPs, or other proteins. Whether syntaxin is involved in docking has been challenged by the finding that genetic knock-out of Drosophila syntaxin failed to impair vesicle docking (Broadie et al., 1995). Furthermore, it has been documented that in PC12 cells large dense core vesicles still accumulate at the plasma membrane after 
Figure 8. Effects of TeNT-LC and BoNT/A-LC on transmitter release in the Retzius $\rightarrow$ P-cell synapse. $A$, Photomicrograph of a Retzius $\rightarrow \mathrm{P}$-cell pair in culture; scale bar, $40 \mu \mathrm{m}$. $B$, Traces show representative recordings obtained before (control) and $40 \mathrm{~min}$ after injection of TeNT-LC $(18 \mu \mathrm{M})$. An action potential in the Retzius cell (top trace, $\left.V_{p r e}\right)$, stimulated by step current injection through the microelectrode (resting membrane potential, $-60 \mathrm{mV}$ ), evoked a postsynaptic potential (PSP) in the P-cell (bottom trace, $V_{\text {post }}$, resting membrane potential $-60 \mathrm{mV}$ ). Microinjection of the toxin into the soma of the Retzius cell produced a block of transmitter release without affecting the action potential waveform or the resting membrane potential. $C$, Time course of inhibition of transmitter release produced by TeNT-LC injection (bar). Synaptic signals were evoked with a frequency of $1 / \mathrm{min}$. The increase in PSP amplitude at the beginning of the recording is attributable to leakage of high $\mathrm{Cl}^{-}$pipette solution into the postsynaptic P-cell. The PSP rate of rise was normalized to the mean rate of rise of the baseline response recorded during the preinjection phase. $D$, Representative recordings obtained before (control) and $40 \mathrm{~min}$ after injection of BoNT/ $A-L C \quad(36 \mu \mathrm{M})$. E, Microinjection of $B o N T / A-L C$ did not affect transmitter release.
A
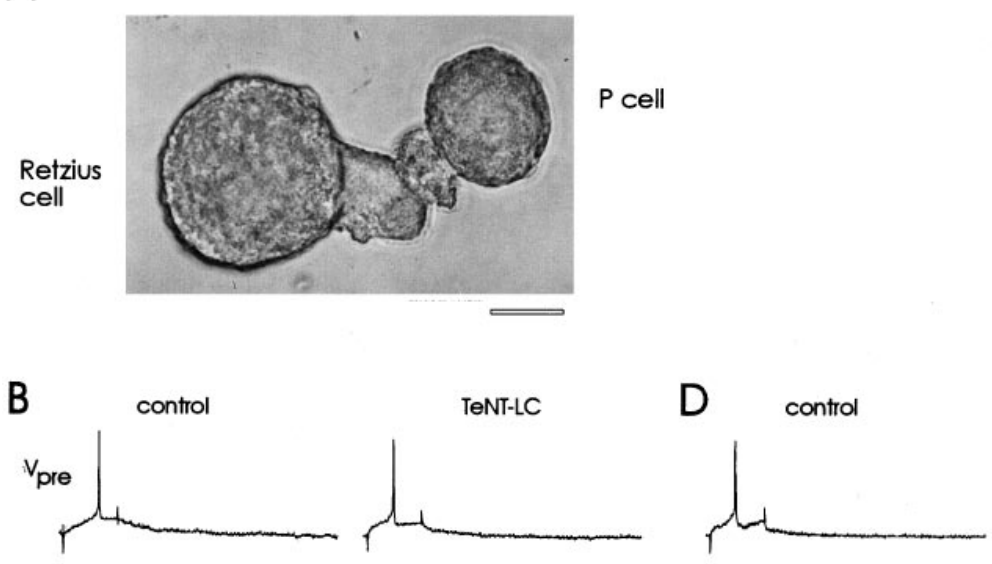

BONT/A-LC
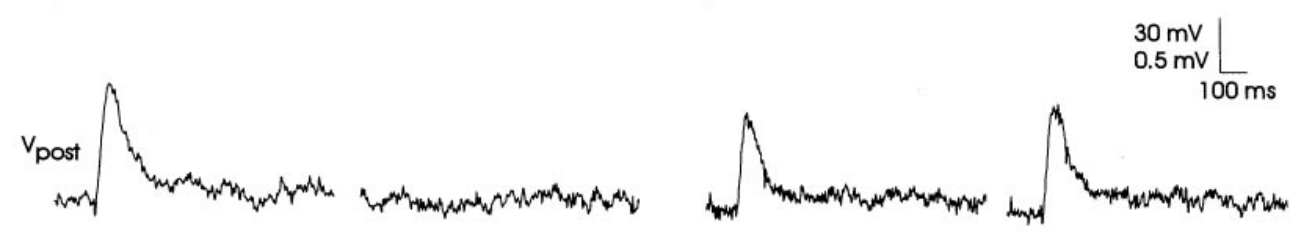

C

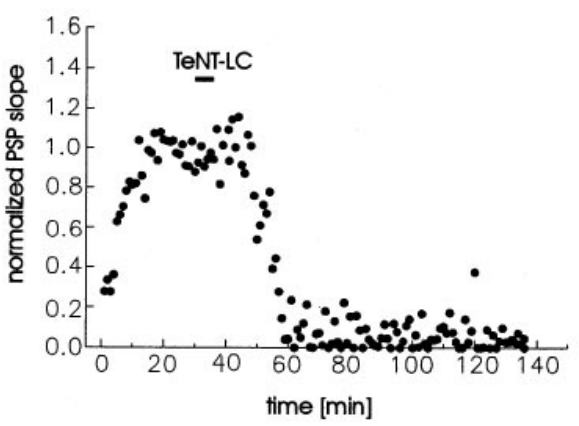

E

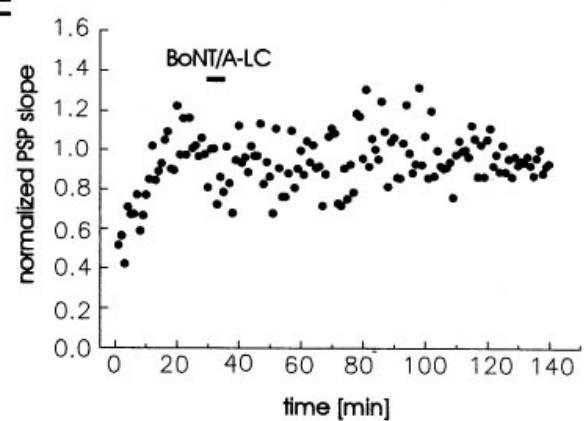

BoNT/A treatment (Banerjee et al., 1996). In summary, the biochemical work, together with the morphological studies, indicates that vesicles can dock despite impaired or absent SNAREs, suggesting that synaptobrevin, syntaxin, and SNAP-25 are involved in events that occur between docking and fusion rather than being directly responsible for vesicle docking.

Previous work demonstrated that the inhibition of transmitter release from rat synaptosomes caused by BoNT/A is associated with proteolysis of SNAP-25 (Blasi et al., 1993a). The resistance of leech SNAP-25 to BoNT/A cleavage was surprising, considering the high degree of homology to its mammalian isoform. Similarly, the protein is insensitive to BoNT/E cleavage (D. Bruns and R. Jahn, unpublished observation). Apparently, the features that confer cleavability of mammalian SNAP-25 are not conserved during evolution. This is not a trivial consideration, because deletion of the last nine amino acids by BoNT/A cleavage disrupts the direct binding of SNAP-25 to synaptobrevin, demonstrating the functional importance of the C-terminal domain (Chapman et al., 1994; Hayashi et al., 1994). It has been proposed that the association of SNAP-25 with synaptobrevin involves the interaction of $\alpha$-helical domains via formation of intermolecular coiledcoil structures (Chapman et al., 1994; Hayashi et al., 1994). Such $\alpha$-helices are distinguished by a characteristic pattern of hydrophobic residues, which are exposed along one side of the helix, generating an intermolecular hydrophobic core in the two- stranded coiled-coil formation (Crick, 1953). Sequence comparison reveals that the periodicity of hydrophobic residues is well preserved in leech SNAP-25, despite the amino acid differences in this domain (Fig. 2B). This may explain how amino acid substitutions in the C-terminal domain of leech SNAP-25 prevent BoNT/A cleavage without affecting the function of the protein. A comparable pattern of unconserved amino acids in this domain also is found in isoforms of Drosophila and in SNAP-23, the recently identified non-neuronal human homolog of SNAP-25 (Fig. 2B). Possibly, BoNT/A resistance is not restricted to SNAP-25 of Hirudo.

Microinjection of BoNT/A into presynaptic Retzius cells did not cause any inhibition of synaptic transmission, whereas similar injections of TeNT-LC produced a clear block of transmitter release. These results are in excellent agreement with our biochemical findings in vitro. However, the susceptibility of substrate proteins toward neurotoxin proteolysis in vitro may differ from that observed in vivo. For example, botulinus toxin $\mathrm{C}$ cleaves syntaxin and also attacks SNAP-25 in intact neurons (Blasi et al., 1993b; Williamson et al., 1996). In contrast, recombinant SNAP-25 is not cleaved in vitro even using concentrations of 500 nM BoNT/C (Foran et al., 1996). Immunoblots of BoNT/A-LCinjected Retzius-P-cell pairs used in our experiments confirmed the resistance of SNAP-25 against proteolytic attack by the toxin in the functioning neuron. Our experiments cannot rule out that 
A

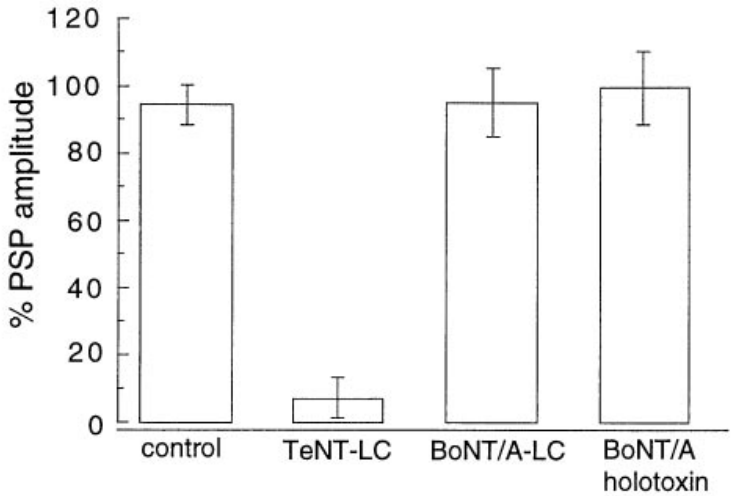

B

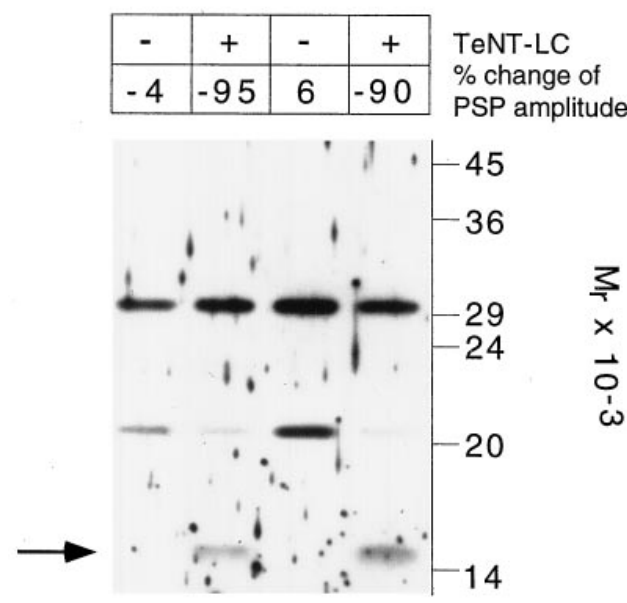

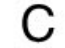
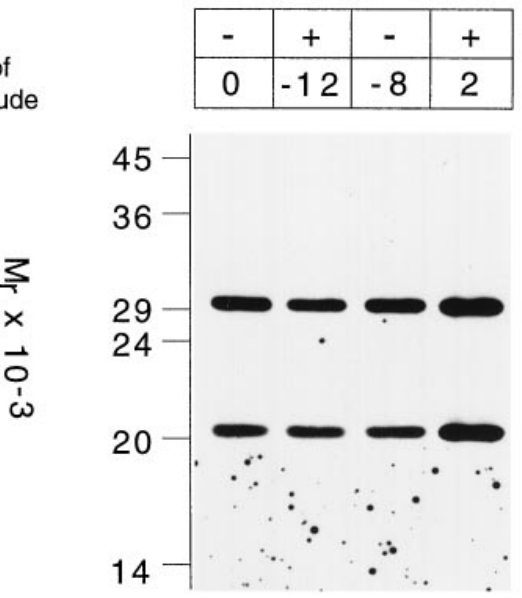

Figure 9. Inhibition of transmitter release correlates with the proteolytic activity of TeNT and BoNT/A in the presynaptic neuron. $A$, Effects of injection of control and toxin solution on the mean PSP amplitude (average response of 10 evoked PSP, second recording) normalized to mean PSP amplitude before injection (first recording). Averaged data from saline (control; $n=10)$, TeNT-LC $(n=8)$, $B o N T / A-L C(n=6)$, and DTT-reduced BoNT/A holotoxin $(n=5)$-injected cell pairs. Note that injection of saline containing DTT was without effect $(n=3$; data not shown). $B, C$, Related immunoblots of single Retzius $\rightarrow$ P-cell pairs injected with toxin light chain $(+)$ or control solution $(-)$. Numbers on top of the gel lane indicate the mean percentage change of the PSP amplitude after injection, measured for the individual cell pair. Synaptobrevin largely is degraded in TeNT-LC-injected neurons $(B)$. The synaptobrevin antibody recognizes a C-terminal cleavage product with an apparent molecular mass of 15 $\mathrm{kDa}$ (arrow). No reduction of SNAP-25 immunoreactivity was observed in BoNT/A-LC-injected pairs $(C)$. Samples were separated on a $15 \%$ SDSpolyacrylamide gel and immunoblotted as described in Figure 3. Blots were stained simultaneously with $S N A P-25$ and Synaptobrevin antibodies. other, hitherto nonidentified, substrate proteins of BoNT/A may exist and have developed a similar resistance to toxin cleavage in this species. Still, on the basis of the present data, we conclude that the corresponding biochemical and physiological results strengthen the hypothesis that SNAP-25 is the sole target protein of BoNT/A.

\section{REFERENCES}

Archer BT, Ozcelik T, Jahn R, Francke U, Südhof TC (1990) Structures and chromosomal locations of two human genes encoding synaptobrevins 1 and 2. J Biol Chem 265:17267-17273.

Banerjee A, Kowalchyk JA, DasGupta BR, Martin TFJ (1996) SNAP-25 is required for a late postdocking step in $\mathrm{Ca}^{2+}$ exocytosis. $\mathrm{J}$ Biol Chem 271:20227-20230.

Bartels F, Bergel H, Bigalke H, Frevert J, Halpern J, Middlebrook J (1994) Specific antibodies against the $\mathrm{Zn}^{2+}$-binding domain of clostridial neurotoxins restore exocytosis in chromaffin cells treated with tetanus or botulinus A neurotoxin. J Biol Chem 269:8122-8127.

Bennett MK, Calakos N, Scheller RH (1992) Syntaxin: a synaptic protein implicated in docking of synaptic vesicles at presynaptic active zones. Science 257:255-259.

Binz T, Blasi J, Yamasaki S, Baumeister A, Link E, Südhof TC, Jahn R, Niemann H (1994) Proteolysis of SNAP-25 by types E and A botulinal neurotoxins. J Biol Chem 269:1617-1620.

Blasi J, Chapman ER, Link E, Binz T, Yamasaki S, De Camilli P, Südhof TC, Niemann H, Jahn R (1993a) Botulinus neurotoxin A selectively cleaves the synaptic protein SNAP-25. Nature 365:160-163.
Blasi J, Chapman ER, Yamasaki S, Binz T, Niemann H, Jahn R (1993b) Botulinus neurotoxin $\mathrm{C} 1$ blocks neurotransmitter release by means of cleaving HPC-1/syntaxin. EMBO J 12:4821-4828.

Bradford MM (1976) A rapid and sensitive method for the quantitation of microgram quantities of protein utilizing the principle of protein-dye binding. Anal Biochem 72:248-254.

Broadie K, Prokop A, Bellen HJ, O'Kane CJ, Schulze KL, Sweeney ST (1995) Syntaxin and synaptobrevin function downstream of vesicle docking in Drosophila. Neuron 15:663-673.

Bruns D, Jahn R (1995) Real-time measurement of transmitter release from single synaptic vesicles. Nature 377:62-65.

Bruns D, Engert F, Lux HD (1993) A fast activating presynaptic reuptake current during serotonergic transmission in identified neurons of Hirudo. Neuron 10:559-572.

Calakos N, Scheller RH (1996) Synaptic vesicle biogenesis, docking, and fusion: a molecular description. Physiol Rev 76:1-29.

Chapman ER, An S, Barton N, Jahn R (1994) SNAP-25, a t-SNARE which binds to both syntaxin and synaptobrevin via domains that may form coiled coils. J Biol Chem 269:27427-27432.

Crick FHC (1953) The packing of $\alpha$-helices: simple coiled-coils. Acta Crystallogr 6:689-697.

DiAntonio A, Burgess RW, Chin AC, Deitcher DL, Scheller RH, Schwarz TL (1993) Identification and characterization of Drosophila genes for synaptic vesicle proteins. J Neurosci 13:4924-4935.

Dietzel ID, Drapeau P, Nicholls JG (1986) Voltage dependence of 5-hydroxytryptamine release at a synapse between identified leech neurons in culture. J Physiol (Lond) 372:191-205.

Drapeau P, Sanchez-Armass S (1988) Selection of postsynaptic serotonin 
receptors during reinnervation of an identified leech neuron in culture. J Neurosci 8:4718-4727.

Edelmann L, Hanson PI, Chapman ER, Jahn R (1995) Synaptobrevin binding to synaptophysin: a potential mechanism for controlling the exocytotic fusion machine. EMBO J 14:224-231.

Elferink LA, Trimble WS, Scheller RH (1989) Two vesicle-associated membrane genes are differentially expressed in the rat central nervous system. J Biol Chem 264:11061-11064.

Ferro-Novick S, Jahn R (1994) Vesicle fusion from yeast to man. Nature 370:191-193.

Foran P, Lawrence GW, Shone CC, Foster KA, Dolly JO (1996) Botulinus neurotoxin $\mathrm{C} 1$ cleaves both syntaxin and SNAP-25 in intact and permeabilized chromaffin cells: correlation with its blockade of catecholamine release. Biochemistry 35:2630-2636.

Fuchs PA, Henderson LP, Nicholls JG (1982) Chemical transmission between individual Retzius and sensory neurons of the leech in culture. J Physiol (Lond) 323:195-210.

Hayashi T, McMahon H, Yamasaki S, Binz T, Hata Y, Südhof TC, Niemann H (1994) Synaptic vesicle membrane fusion complex: action of clostridial neurotoxins on assembly. EMBO J 13:5051-5061.

Hess DT, Slater TM, Wilson MC, Skene JHP (1992) The $25 \mathrm{kDa}$ synaptosomal-associated protein SNAP-25 is the major methionine-rich polypeptide in rapid axonal transport and a major substrate for palmitoylation in adult CNS. J Neurosci 12:4634-4641.

Higuchi R (1990) Recombinant PCR. In: PCR protocols: a guide to methods and applications (Innis MA, Gelfand DH, Sinisky JJ, White TJ, eds), pp 177-183. New York: Academic.

Hunt JM, Bommert K, Charlton MP, Kistner A, Habermann E, Augustine GJ, Betz H (1994) A post-docking role for synaptobrevin in synaptic vesicle fusion. Neuron 12:1269-1279.

Jahn R, Schiebler W, Ouimet C, Greengard P (1985) A 38,000 dalton membrane protein (p38) present in synaptic vesicles. Proc Natl Acad Sci USA 82:1374-1388.

Köhler G, Milstein C (1975) Continuous cultures of fused cells secreting antibody of predefined specificity. Nature 256:495-497.

Laemmli UK (1970) Cleavage of structural proteins during the assembly of the head of bacteriophage T4. Nature 227:680-685.

Link E, Edelmann L, Chou JH, Binz T, Yamasaki S, Eisel U, Baumert M, Südhof TC, Niemann H, Jahn R (1992) Tetanus toxin action: inhibition of neurotransmitter release linked to synaptobrevin proteolysis. Biochem Biophys Res Commun 189:1017-1023.

Liu Y, Nicholls J (1989) Steps in the development of chemical and electrical synapses by pairs of identified leech neurons in culture. Proc R Soc Lond [Biol] 236:253-268.

Llinás R, Sugimori M, Morita M, Blasi J, Hereros J, Jahn R, Marsal J (1993) Transmission at the squid giant synapse was blocked by tetanus toxin by affecting synaptobrevin, a vesicle-bound protein. J Physiol (Lond) 477:129-133.

Maisey EA, Wadsworth JDF, Poulain B, Shone CC, Melling J, Gibbs P, Tauc L, Dolly JO (1988) Involvement of the constituent chains of botulinus neurotoxins $\mathrm{A}$ and $\mathrm{B}$ in the blockade of neurotransmitter release. Eur J Biochem 177:683-691.

Mayer A, Wickner W, Haas A (1996) Sec18p (NSF)-driven release of Sec17p ( $\alpha$-SNAP) can precede docking and fusion of yeast vacuoles. Cell 85:83-94.

Mochida S, Poulain B, Weller U, Habermann E, Tauc L (1989) Light chain of tetanus toxin intracellularly inhibits acetylcholine release at neuro-neuronal synapses, and its internalization is mediated by heavy chain. FEBS Lett 253:47-51.

Montecucco C, Schiavo G (1994) Mechanism of action of tetanus and botulinus neurotoxins. Mol Microbiol 13:1-8.

Mundigl O, Verderio C, Kraszewski K, De Camilli P, Matteoli M (1995) A radioimmunoassay to monitor synaptic activity in hippocampal neurons in vitro. Eur J Cell Biol 66:246-256.

NiemannH (1991) Molecularbiology of clostridial neurotoxins. In:Sourcebook of bacterial toxins (Alouf JE, Freer JE, eds), pp 303-348. New York: Academic.

Niemann H, Blasi J, Jahn R (1994) Clostridial neurotoxins: new tools for dissecting exocytosis. Trends Neurosci 4:179-185.

Osen-Sand A, Staple JK, Naldi E, Schiavo G, Rosetto O, Petitpierre S, Malgaroli A, Montecucco C, Catsicas S (1996) Common and distinct fusion proteins in axonal growth and transmitter release. J Comp Physiol [A] 367:222-234.
Oyler GA, Higgins GA, Hart RA, Battenberg E, Billingsley M, Bloom FE, Wilson MC (1989) Identification of a novel synaptosomal-associated protein SNAP-25, differentially expressed by neuronal subpopulations. J Cell Biol 109:3039-3052.

Pelligrini LL, O'Connor V, Lottspeich F, Betz H (1995) Clostridial neurotoxins compromise the stability of a low energy SNARE complex mediating NSF activation of synaptic vesicle fusion. EMBO J 14: 4705-4713.

Pevsner J, Hsu S-C, Braun JEA, Calakos N, Ting AE, Bennet MK, Scheller RH (1994) Specificity and regulation of synaptic vesicle docking. Neuron 13:353-361.

Poulain B, Mochida S, Wadsworth JDF, Weller U, Habermann E, Dolly JO, Tauc L (1990) Inhibition of neurotransmitter release by botulinus neurotoxins and tetanus toxin at Aplysia synapses: role of constituent chains. J Physiol (Paris) 84:247-261.

Ravichandran V, Chawla A, Roche PA (1996) Identification of a novel syntaxin- and synaptobrevin/VAMP-binding protein, SNAP-23, expressed in non-neuronal tissues. J Biol Chem 271:13300-13303.

Risinger C, Blomquist AG, Lundell I, Lambertson A, Nässel D, Pieribone VA, Brodin L, Larhammer D (1993) Evolutionary conservation of synaptosome-associated protein $25 \mathrm{kDa}$ (SNAP-25) shown by Drosophila and Torpedo clones. J Biol Chem 268:24408-24414.

Rothman JE, Wieland FT (1996) Protein sorting by transport vesicles. Science 272:227-234.

Saiki RK, Gelfand DH, Stoffel S, Scharf SJ, Higuchi R, Horn GT, Mullis KB, Ehrlich HA (1988) Primer-directed enzymatic amplification of DNA with a thermostable DNA polymerase. Science 239:487-491.

Sanger F, Nicklen S, Coulson AR (1977) DNA sequencing with chain termination inhibitors. Proc Natl Acad Sci USA 74:5463-5467.

Schägger H, von Jagow G (1987) Tricine-sodium dodecyl sulfatepolyacrylamide gel electrophoresis for the separation of proteins in the range from 1 to $100 \mathrm{kDa}$. Anal Biochem 166:368-379.

Schiavo G, Benfenati F, Poulain B, Rosetto O, Polverino de Laureto P, DasGupta B, Montecucco C (1992) Tetanus and botulinus-B neurotoxins block neurotransmitter release by proteolytic cleavage of synaptobrevin. Nature 359:832-835.

Schiavo G, Rosetto O, Catsicas S, Polverino de Laureto P, DasGupta BR, Benfenati F, Montecucco C (1993) Identification of the nerve terminal targets of botulinus neurotoxin serotypes A, D, and E. J Biol Chem 268:23784-23787.

Söllner T, Whiteheart SW, Brunner M, Erdjument-Bromage H, Geromanos S, Tempst P, Rothman JE (1993a) SNAP receptors implicated in vesicle targeting and fusion. Nature 362:318-323.

Söllner T, Bennet MK, Whiteheart SW, Scheller RH, Rothman JE (1993b) A protein assembly-disassembly pathway in vitro that may correspond to sequential steps of synaptic vesicle docking, activation, and fusion. Cell 75:409-418.

Südhof TC (1995) The synaptic vesicle cycle: a cascade of protein-protein interactions. Nature 375:645-653.

Südhof TC, Baumert M, Perin MS, Jahn R (1989) A synaptic vesicle membrane protein is conserved from mammals to Drosophila. Neuron 2:1475-1481.

Sweeney ST, Broadie K, Keane J, Niemann H, O'Kane CJ (1995) Targeted expression of tetanus toxin light chain in Drosophila specifically eliminates synaptic transmission and causes behavioral defects. Neuron 14:341-351.

Trimble WS, Cowan DM, Scheller RH (1988) VAMP-1: a synaptic vesicle-associated integral membrane protein. Proc Natl Acad Sci USA 85:4538-4542.

Veit M, Söllner TH, Rothman JE (1996) Multiple palmitoylation of synaptotagmin and the t-SNARE SNAP-25. FEBS Lett 385:119-123.

Walch-Solimena C, Blasi J, Edelmann L, Chapman ER, Fischer von Mollard G, Jahn R (1995) The t-SNARE syntaxin 1 and SNAP-25 are present on organelles that participate in synaptic vesicle recycling. J Cell Biol 128:637-645.

Williamson LC, Halpern JL, Montecucco C, Brown JE, Neale EA (1996) Clostridial neurotoxins and substrate proteolysis in intact neurons. J Biol Chem 271:7694-7699.

Yamasaki S, Hu Y, Binz T, Kalkuhl A, Kurazano H, Tamura T, Jahn R, Kandel E, Niemann H (1994) Synaptobrevin/vesicle-associated membrane protein (VAMP) of Aplysia californica: structure and proteolysis by tetanus toxin and botulinal neurotoxins type D and F. Proc Natl Acad Sci USA 91:4688-4692. 